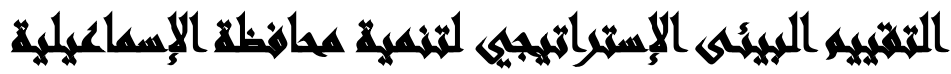

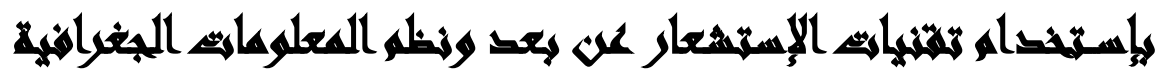

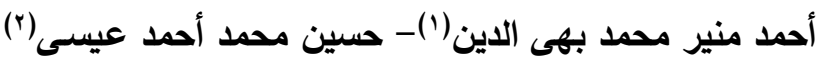

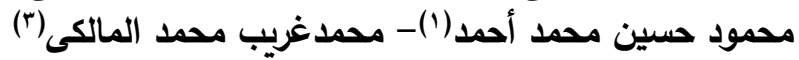

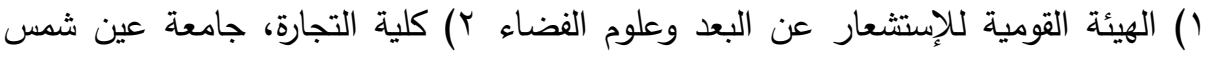

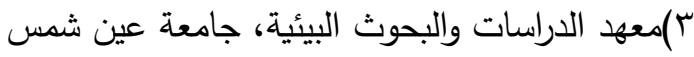

\section{المستخلصى}

يهدف البحث إلي دراسة التقييم البيئي الاستراتيجي وإعداد مصفوفة الأهداف البيئية الإستراتيجية الثاملة مع الإثارة إلي أهمية تفعيل الدور البيئي بين أبعاد التتمية (الاجتماعية

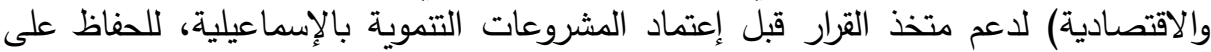

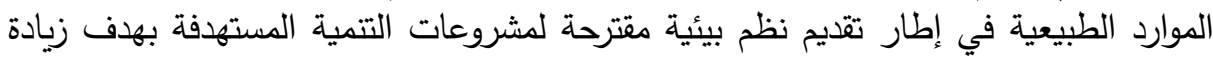

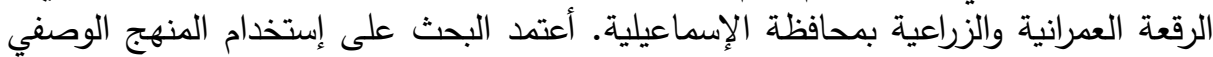

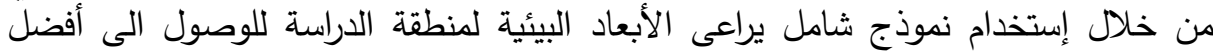

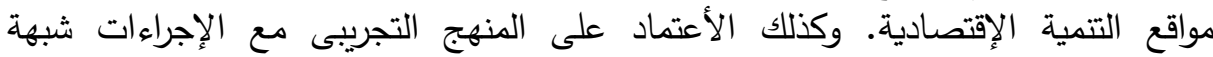

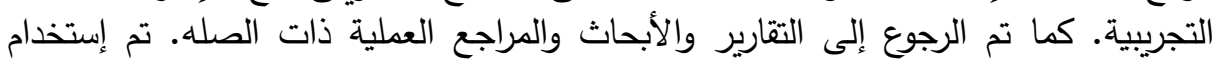

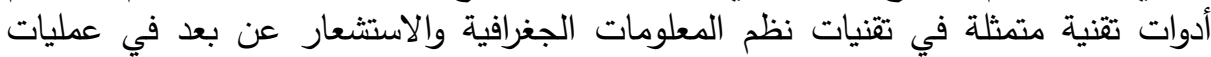

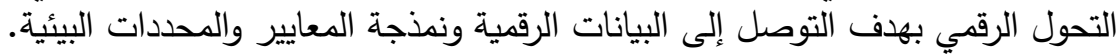

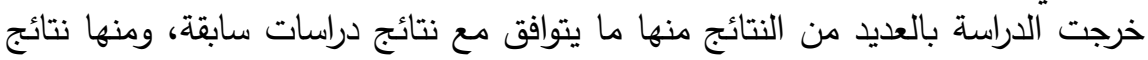

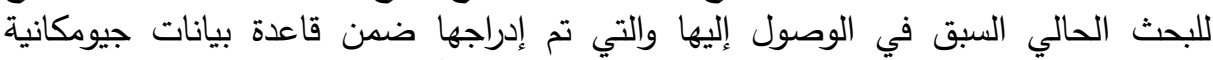

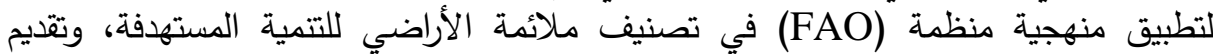
مخطط التتمية المستدامة المقترح مع الحفاظ على الهئ الأنثطة الإقتصادية القائمة والإستغلال الأمثل للموارد (الطبيعية/البشرية) المتاحة بالبئية البئة.

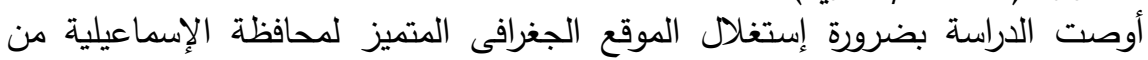

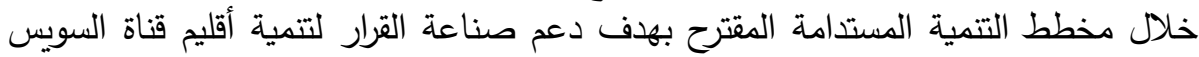

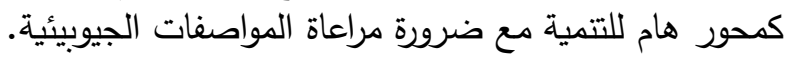

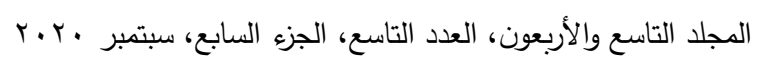




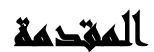

أهتم البحث بدراسة التقييم البيئى الإستراتيجي بحافظة الإسماعيلية والتعرف على الإنى

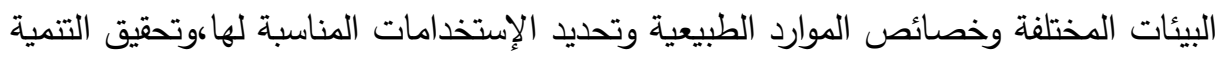
المستدامة والحيلولة دون وقوع إضطرابات بيئية بالبيئة الدحيطة.

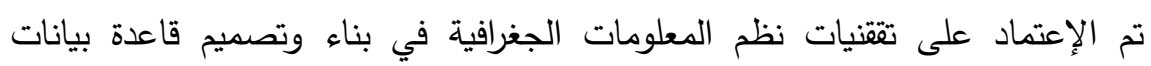

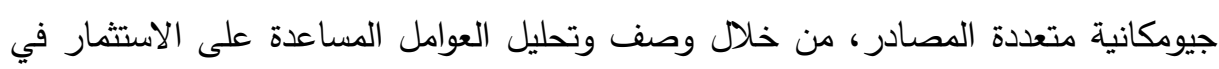

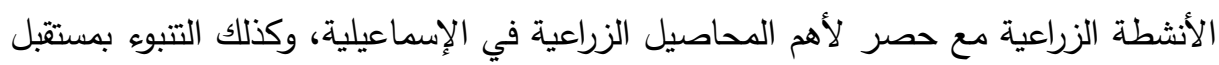

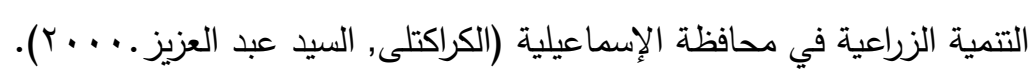

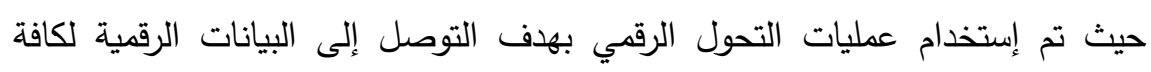

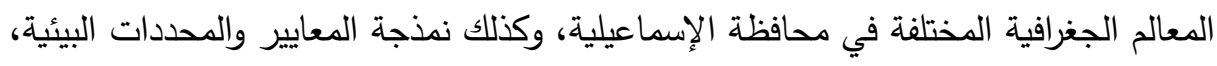

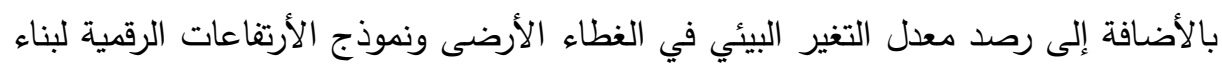
وتفعيل النماذج الرقمية لإختيار أفضل مواقع التتمية وفقا للمعايير والمحددات البيئية.

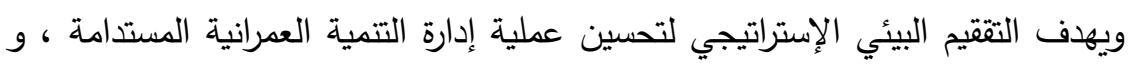

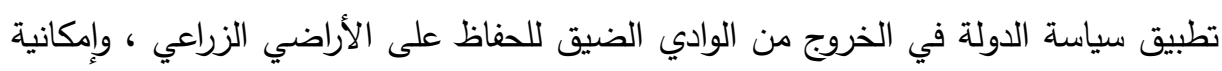

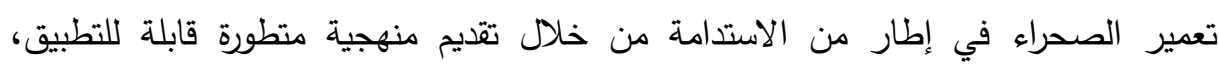

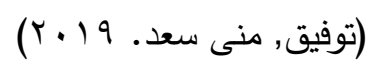
من خلال تطبيق معايير الجودة البيئية واجراء مصفوفة تحليل السياسات للمحاصيل

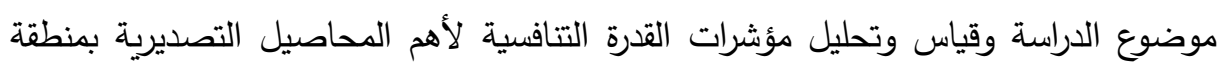

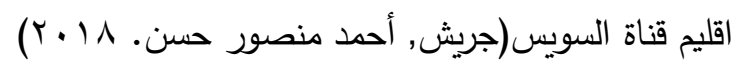

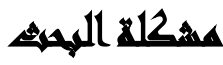

416

$$
\begin{aligned}
& \text { r. . . • المجلد التاسع والأربعون، العدد التاسع، الجزء السابع، سبتمبر }
\end{aligned}
$$

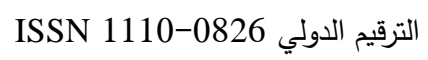


تعد أهمية المشروعات التتموية الضخمة إلى دفع عجلة الاقتصاد وإستغلال الأمثل للموارد

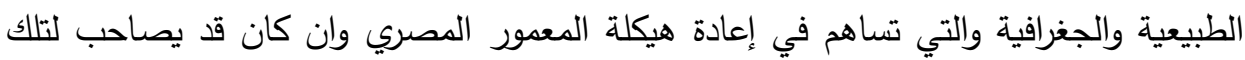
المشروعات المستهدفة بعض الاثار البيئية والتي تهتم الدراسة بتوضيحها بهدف المساديه لهاهمة في

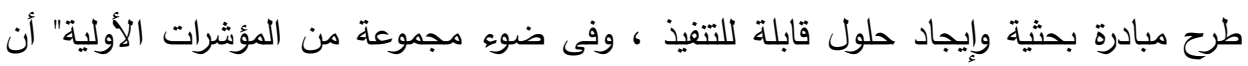

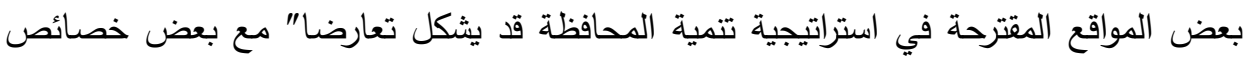

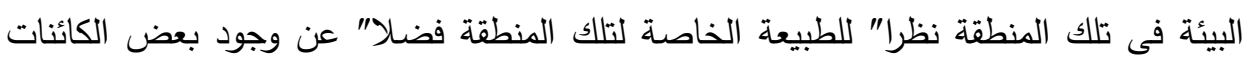
الحية النادرة والتي تعد مهدده في حالة زيادة الحمل البيئي مستقبلا"، ولذا يجب النئ أن يتم تحديد الأنثطة والتكنولوجيا المستخدمة وفقا'للبيئة المحيطة. المحور الاول: مخاطر بيئية تزيد القيمة الإجمالية للتكلفة الاقتصادية:

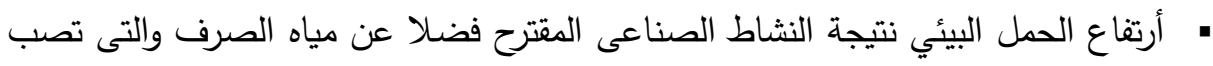

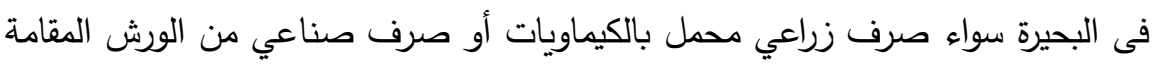

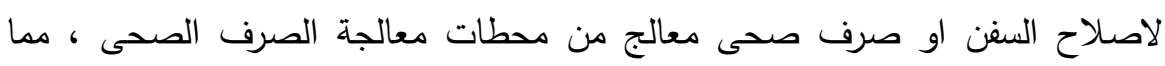
يستلزم معه العمل على انشاء محطات تتقية للحفاظ على المورد المائى.

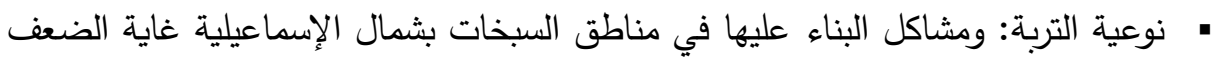

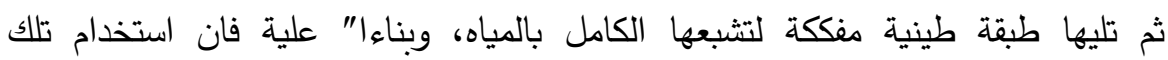

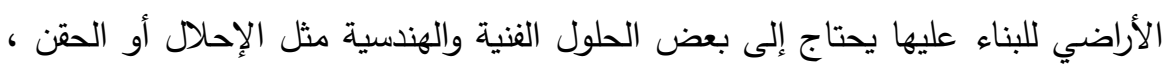
مما سيؤدى إلى زيادة التكلفة الأقتصادية للمشروعات على تلى تلك الأراضي.

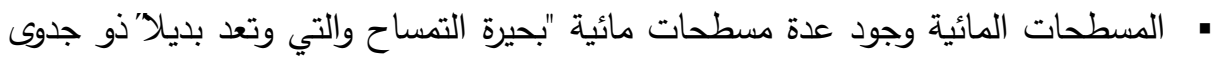

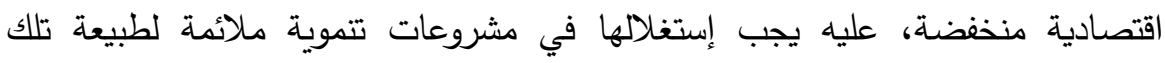
الأراضي مثل أنشطة الأستزراع السمكي. • التتوع البيولوجي وحماية مناطق البيئة: حيث تتميز محافظة الاسماعيلية بأنها من

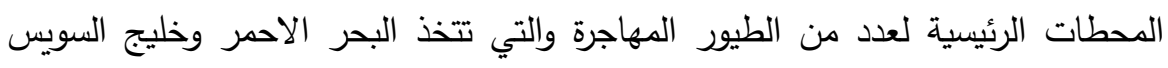

$$
\begin{aligned}
& \text { r. . . المجلد التاسع والأربعون، العدد التاسع، الجزء السابع، سبتمبر }
\end{aligned}
$$

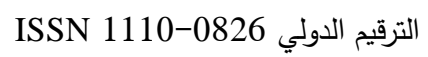




$$
\begin{aligned}
& \text { مجلة العلوم البيئية } \\
& \text { معهد الدراسات والبحوث البيئية - جامعة عين شمس له } \\
& \text { أحمد منير بهي الدين وآخرون }
\end{aligned}
$$

طريقا" لهجرتها شمالا، والتى تعد لتكون أحد المناطق الواعدة لمستقبل السياحة البيئية فى المحور الثاني: إهدار عدة موارد طبيعية وأنشطة إقتصادية:

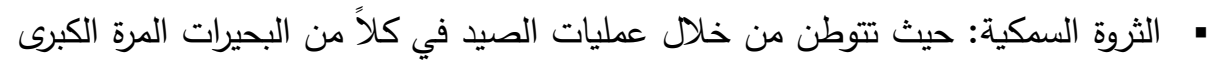
والصغرى وبحيرة التمساح وقناة السويس والتي تعد الركيزة الأساسية لنشاط الثروة السمكية بالمحافظة كذلك نشاط الاستزراع السمي بالأراضي المتاخمة للبحيرات والتي أسفرت

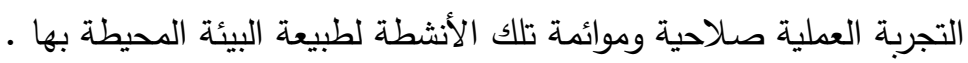

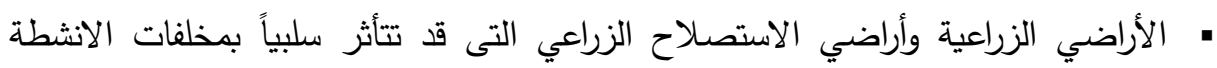

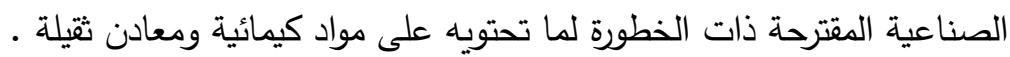

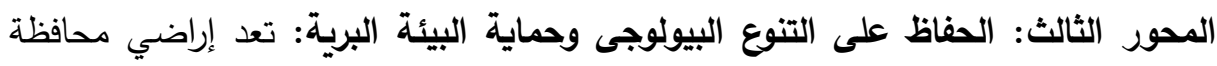
الإسماعيلية أحد المناطق الواعدة لمستقبل السياحة البيئية فى مصر حيث تمثله البهل الأراضى المصرية المعبر اليابس الوحيد بين ثلاث قارات ( أوربا وآسيا وأفريقيا ) ، فهى إحدى الحئ أهم طرق هجرة الطيور فى العالم حيث تعبر ملايين من الطيور المهجرة خلال رحلتها وتقضى لئى

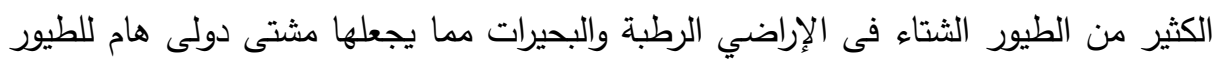

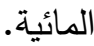

\section{أسريلة المهنش}

التساؤل الرئيسي للدراسة "كيف يمكن تفعيل إستراتيجية الدولة في تطبيق المشروعات

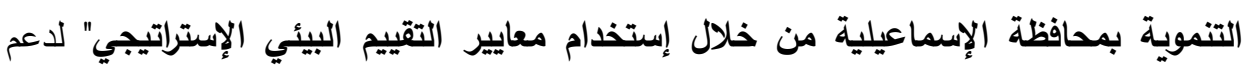

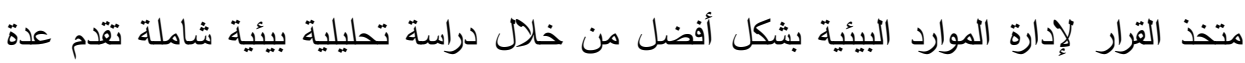
بدائل مقترحة تهدف إلى التتبوء بالعديد من المخاطر البيئية وتهدف إلى تقديم النظم البيئية المقترحة في إطار التتمية المستدامة؟ لبه

$$
\begin{aligned}
& \text { r. r. • المجلد التاسع والأربعون، العدد التاسع، الجزء السابع، سبتمبر } \\
& \text { الترقيم الدولي 0826-0 الإنون، }
\end{aligned}
$$




$$
\begin{aligned}
& \text { مجلة العلوم البيئية } \\
& \text { معهد الدراسات والبحوث البيئية - جامعة عين شمس لكس } \\
& \text { أحمد منير بهي الدين وآخرون }
\end{aligned}
$$

ثانيا': التساؤلات الفرعية للدراسة:

• ما هي المقومات البيئية والموارد الطبيعية بمحافظة الإسماعليلية؟ • ما هي المخاطر البيئية المتوقعة والتي تتعكس على زيادة القيمة الإجمالية للتكلفة الاقتصادية

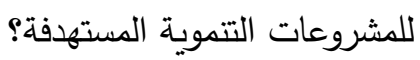
• ما هي الأهداف البيئية الإستراتيجية التي يجب مراعتها في إختيار وتحديد المشروعات

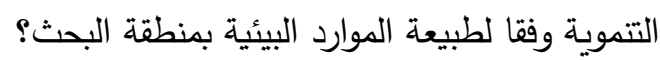

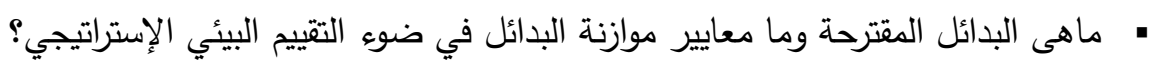
• ما هي النظم البيئية المقترحة لبديل التنمية المستدامة؟ هواله

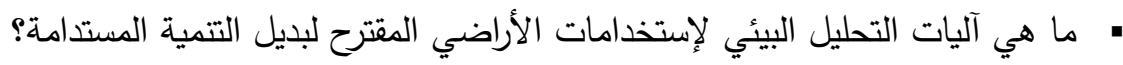

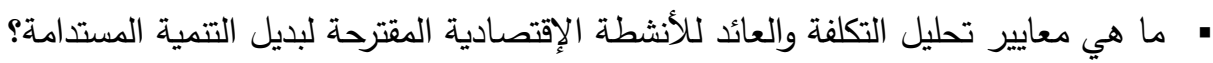

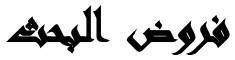

ا. توجد علاقة طردية حيث يرتفع معدل التلوث البيئي بمنطقة البحث نتيجة زيادة الحمل البيئي وزيادة التكاليف البيئية كنتيجة طبيعية لارتفاع معدلات التلوث البيئي في منطقة

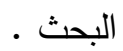
r. توجد علاقة إرتباطية بين ارتفاع القيمة الإجمالية للتكاليف الإقتصادية للمشروعات التتموية نظرا لطبيعة الإراضي الرطبة فى منطقة البحث مما يجعلها ذات جدوى اقتصادية منخفضة. r. وجود خسارة إقتصادية نتيجة لعدم إستغلال الجانب الشرقي من منطقة البحث فى أنشطة

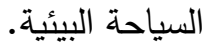

\section{أهمبر البهan}

$$
\begin{aligned}
& \text { r.r. المجلد التاسع والأربعون، العدد التاسع، الجزء السابع، سبتمبر } \\
& \text { الترقيم الدولي 0826- ISSN 1110 }
\end{aligned}
$$




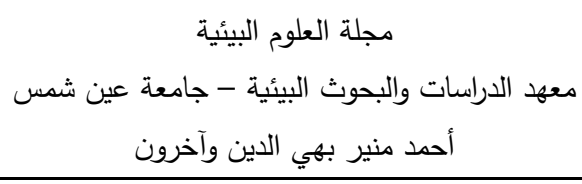

• ترجع أهمية البحث إلى الإهتمام بدراسات التقييم البيئي الإستراتيجي مع إيضاح البعد

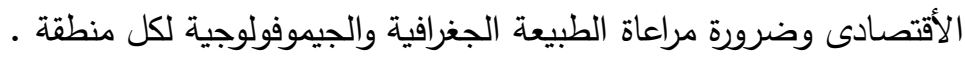
• إستخدام تقنيات الأستشعار من البعد ونظم المعلومات الجغرافية وتحليل مرئيات الأقمار

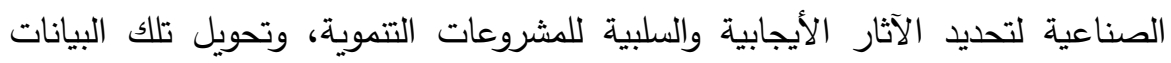
الرقمية إلى بيانات كمية لتحديد البعد الإقتصادى وإستخدام أسلوب تحليل التكلفة والعائد، فيبرز مطلب الحفاظ على معالم البيئة كمشكلة إقتصادية . • بناء قاعدة بيانات جيومكانية متعددة المصادر تشمل كافة الطبقات الجغرافية والمكانية والوصفية والدليلية الخاصة بمنطقة البحث بهدف إستخدامها في عمليات التحليل والنمذجة الرقمية. • تعيل إستخدام النمذجة الرقمية لتحديد الموقع الأفضل للتنمية من خلال التحليل المكاني لرصد معدلات التغيير البيئي في الغطاء الأرضي، والتحليل المكاني الطبوغرافي، والتحليل

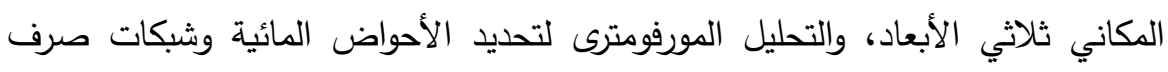

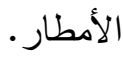
- بناء مصفوفة موازنة البدائل البيئية وفقا للأهدفا الإستراتيجية في عمليات التقييم البيئي بهدف إختيار البديل الأمثل وفقا لنتائج التحليلات الثاملة.

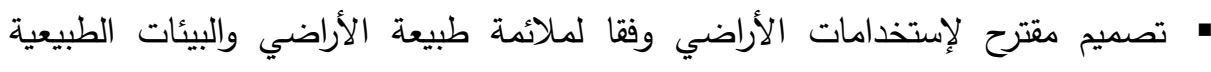

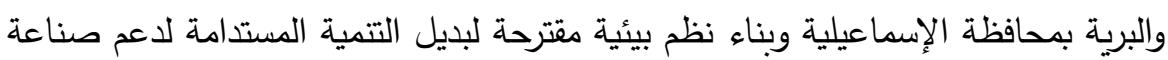
إتخاذ القرار •

• تدعم دراسة التقييم البيئي الإستراتيجي صناعة إتخاذ القرار من خلال تقديم دراسة تحليلة بيئية تقدم عدة بدائل تنموية مقترحة للمشروعات التتموية المستهدفة لدحافظة الإسماعيلية وفقا لنظم التتيمة البيئية المستدامة ضمن إستراتيجية التتمية لأقليم قناة السويس.

\section{Aath}

420

$$
\begin{aligned}
& \text { r. r. • المجلد التاسع والأربعون، العدد التاسع، الجزء السابع، سبتمبر }
\end{aligned}
$$

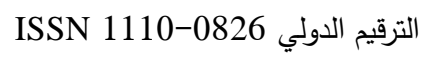




$$
\begin{aligned}
& \text { مجلة العلوم البيئية } \\
& \text { معهد الدراسات والبحوث البيئية - جامعة عين شمس لكس } \\
& \text { أحمد منير بهي الدين وآخرون }
\end{aligned}
$$

الحد المكانى : منطقة الحدود الإدارية لمحافظة الإسماعيلية.

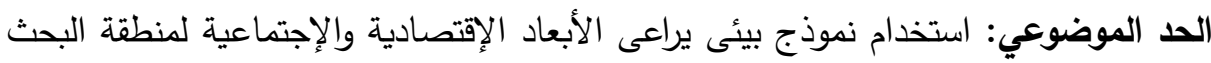

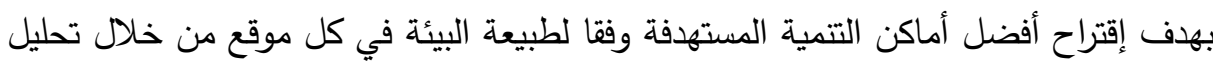

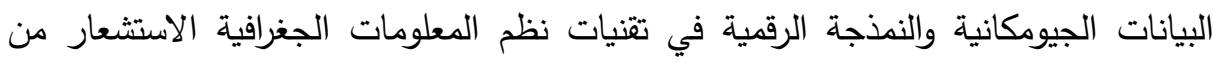

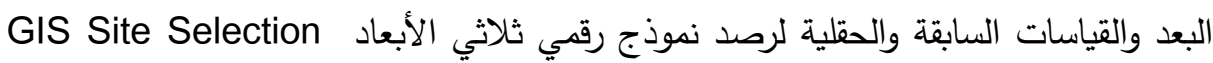
لإختيار افضل أماكن التتمية مع تحويل تلك البيانات الرقمية إلى بيانات كمية لتصدية بالاعتماد على أسلوب تحليل التكلفة والعائد لتحديد البعد الاقتصادي لبديل التتمية المستدامة. الحد الزمنى: رصد وتقييم بيئى وحساب معدلات التغيير في الغطاء الإرضي من خلال تحليل ونمذجة بيانات مرئيات الأقمار الصناعية فى عدة تواريخ متعاقبة لمنطقة البحث.

\section{أهساهث الهمبه}

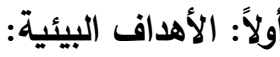

ا. دراسة التقييم البيئي الاستراتيجي وإعداد مصفوفة الأهداف البيئية الإستراتيجية الثاملة مع تفعيل الدور البيئي بين أبعاد التتمية الأخرى (الاجتماعية والاقتصادية) لدعم متخذ القرار . r. الحفاظ على الموارد الطبيعية في إطار تقديم نظم بيئية مقترحة تهدف إلي تحقيق التتمية المستدامة، من خلال الاعتماد على تكنلوجيا الإنتاج الأنظف صديقة.

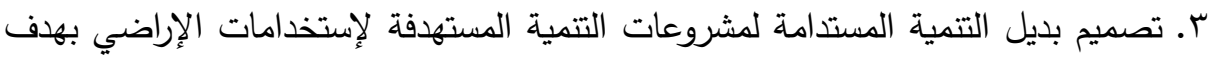
زيادة الرقعة العمرانية والزراعية بمحافظة الإسماعيلية ودعم إستراتيجية الدولة بزيادة

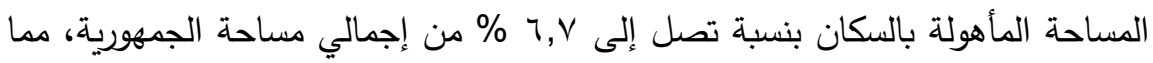

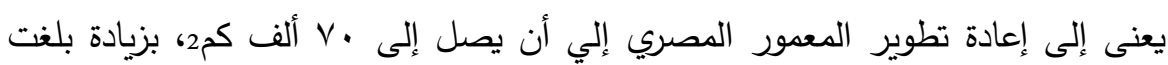

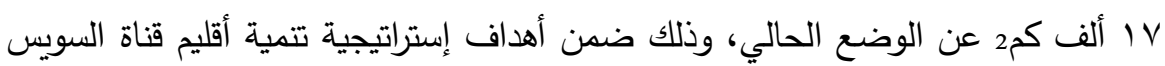

$$
\begin{aligned}
& \text { r.r. · المجلد التاسع والأربعون، العدد التاسع، الجزء السابع، سبتمبر } \\
& \text { الترقيم الدولي 0826- ISSN 1110 }
\end{aligned}
$$


ثانياً: الأهداف الإستراتيجية والإقتصادية:

ا. التوظيف الأمثل للموارد الإقتصادية بمحافظة الإسماعيلية مع ضرورة استغلال الموقعاديه

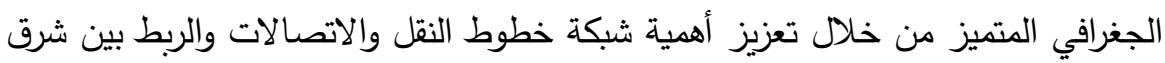
وغرب قناة السويس، كمحور قومي للتنمية دع ضرورة مراعاة المواصفات الجيوبيئية

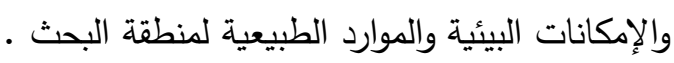
r. العمل على جذب مشروعات التتموية إلى المناطق المناسبة وتتمية البنية التحتية لتشجيع الهجرة من المناطق المتوقع تأثرها الى المناطق الامنة، مع إتاحة التمويل اللازم لإقامة

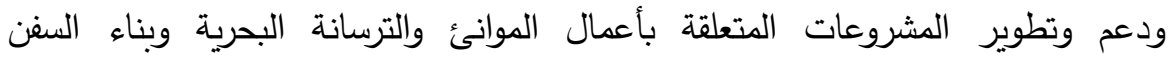
والأنشطة المرتبطة، ومنح تسهيلات مصرفية للمشروعات المقامة عليها لتشجيع التصنيع والتصدير - والانسط r. دراسة كيفية تجنب التكاليف الباهظة التى تحتاجها مناطق الأراضي الرطبة والطفح المائى وتغدق التربة لإعادة تأهيلها لتكون صالحة للتمية، عن طريق الاختيار بين البدائل وتحديد

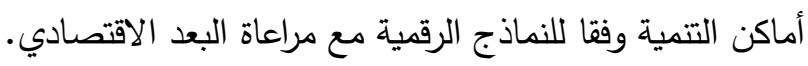

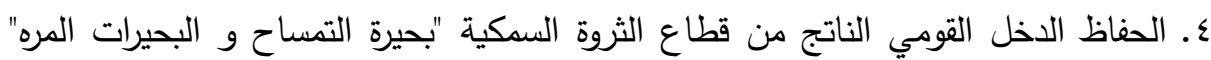
بمساحة . . . ــ فدان تقريباً ، مع إمكانية تتمية وتطوير نشاط الاستزراع السمكي بتخصيص مناطق متاخمة للبحيرات والإراضي الرطبة كإمتداد طبيعي يتم الاستثمار فيها مستقبلا، مع مراعاة الاشتراطات البيئية في تحديد مواقع تلك التتمية.

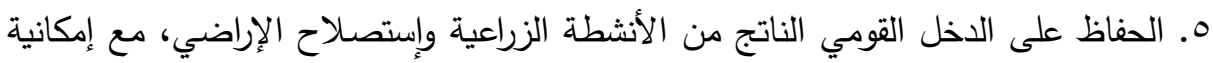

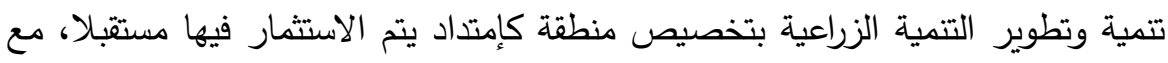
مراعاة الاشتراطات البيئية في تحديد مواقع التتمية.

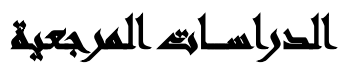

$$
\begin{aligned}
& \text { r. r. • المجلد التاسع والأربعون، العدد التاسع، الجزء السابع، سبتمبر }
\end{aligned}
$$

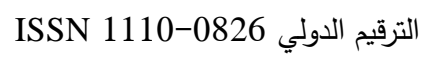




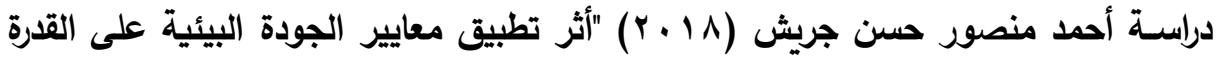
التنافسية للصادرات الزراعية بالتطبيق على القطاع الزراعى بمنطقة اقليم محافظات القناة". أشارت البحث إلى يهدف البحث الى دراسة أثر تطبيق معايير الجودة البيئية على القدرة

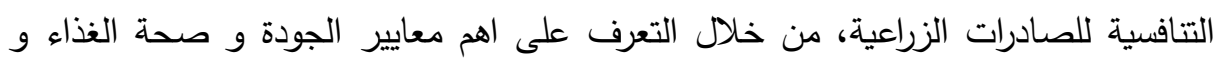
تصنيفها واثرها على التجارة الدولية، مع توضيح مفهوم القدرة التتافسية وانواعها ومحدداتها

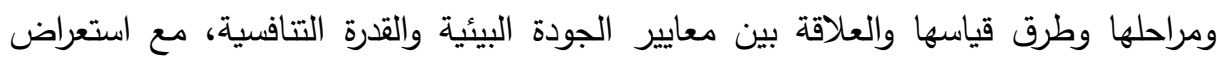

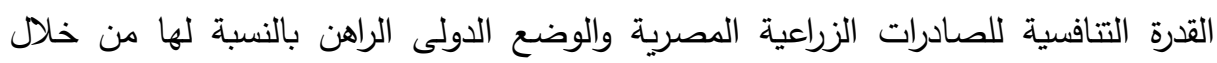
دراسة تحليل تكاليف الجودة واثرها على تتافسية المنتج واجراء مصفوفة تحليل السياسات للمحاصيل موضوع البحث وقياس وتحليل مؤشرات القدرة التتافسية لأهم المحاصيل التصديرية بمنطقة اقليم قناة السويس.

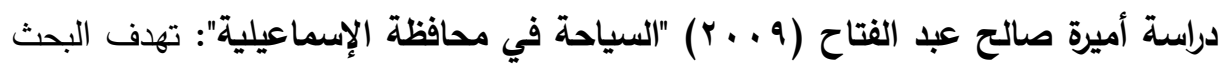

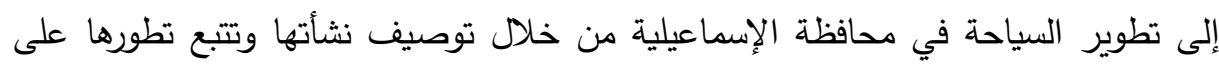
مدار السنوات الماضية مع توصيف وتحليل المقومات الطبيعية في الإسماعيلية ومدى تأثيرها

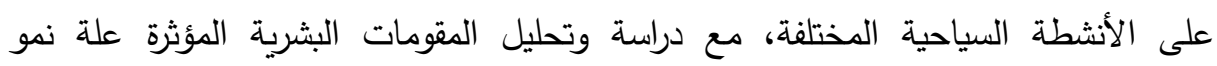
الأنشطة السياحية ، مع تقديم تتبوء بمستقبل السياحة في منطقة البحث.

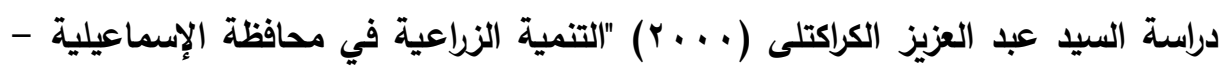

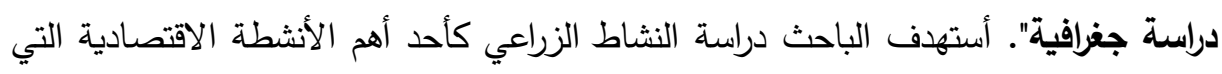

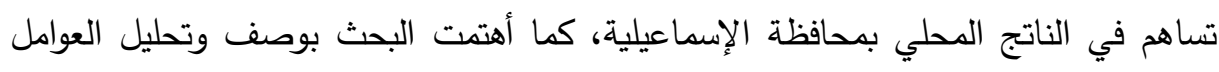

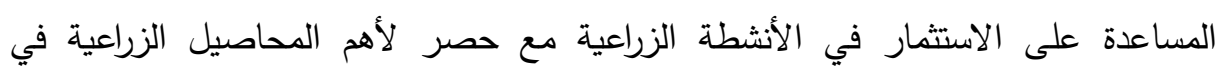
الإسماعيلية، وكذلك تتبوء بمستقبل التتمية الزراعية في محافظة الإسماعيلية.

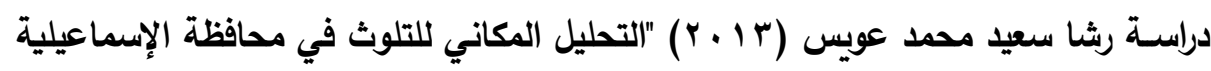
باستخدام نظم المعلومات الجغرافية والاستشعار من البعد". أستهدفت هذه البحث البعائ التحليل

$$
\begin{aligned}
& \text { r. . . المجلد التاسع والأربعون، العدد التاسع، الجزء السابع، سبتمبر }
\end{aligned}
$$

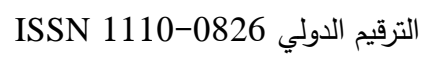


المكاني للتلوث بمحافظة الإسماعلية من خلال استخدام تقنيات الاستشعار واستخدام ونظم

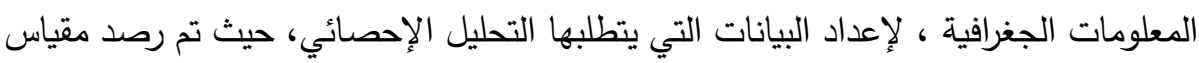
التشتت ومقياس النزعة المركزية للبيانات الوصفية وربطها بالبيانات المكانية.

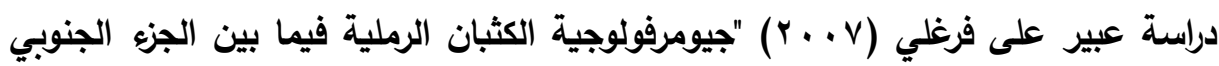
من الإسماعيلية والحافة الغربية لهضبة التيه سيناء". أظهرت البحث تلوع التكوينات

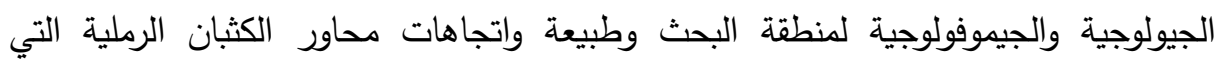
تغطيها، والتي لها تأثير على التتمية الاقتصادية.

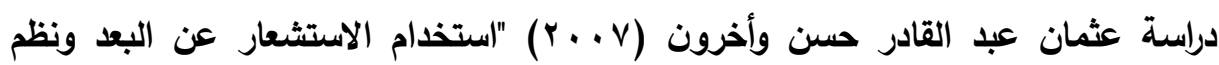
المعلومات الجغرافية لرصد ونمذجة الزحف العمراني على الأراضي الزراعية بمحافظتي

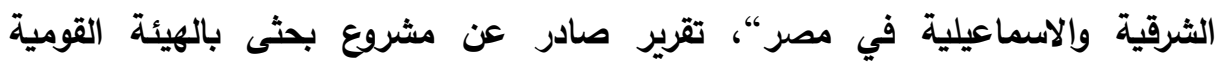

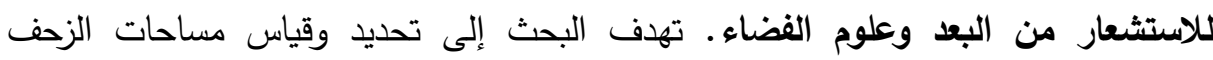

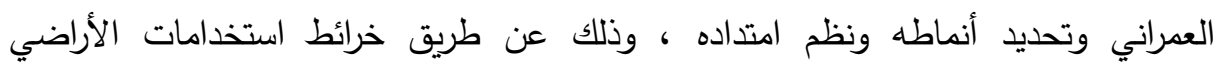

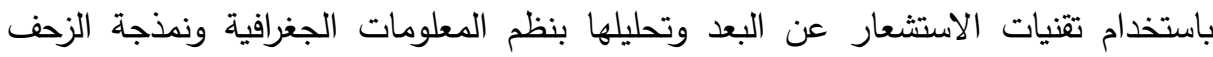
العمراني، وذلك لفهم ديناميكية ظاهرة الزحف العمراني في محافظتي (الثرقية / الإسماعيلية) منطقة البحث .

دراسـة منى سعد توفيق (19 ب ب) "التنمية العمرانية المستدامة في محافظة الإسماعيلية بإستخدام نظم المعلومات الجغرافية والإستشعار من البعد دراسة في التخطيط الحضري".

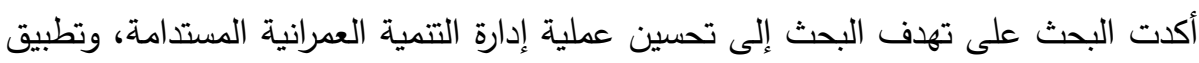
سياسة الدولة في الخروج من الوادي الضيق للحفاظ على الأراضي الزراعي ، وإمكانية تعمير

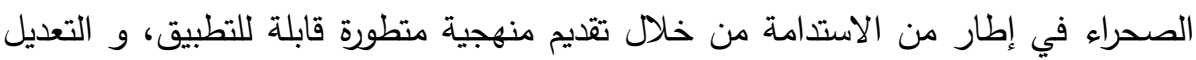

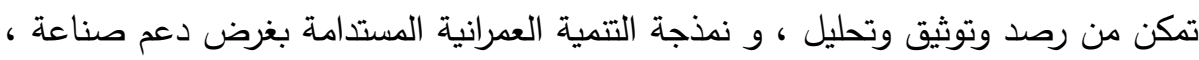

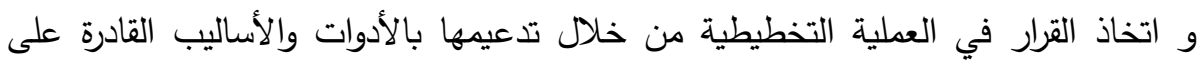

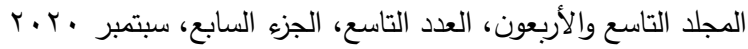

$$
\begin{aligned}
& \text { الترقيم الدولي 0826- ISSN 1110 }
\end{aligned}
$$


رصدها وتوثيقها و تحليلها والنمذجة الكارتوجرافية لها، أقترحت البحث عدة سيناريوهات والتي تمكنها من إستباق أو ترشيد العديد من المخاطر التي تحيط بهذه التتمية مما يتيح اتخاذ مجموعة من السياسات والإجراءات للحد من العواقب المقترنة بهذه التتمية قبل وضعها بحيز لهنيل

التتفيذ.

\section{الإطار اللنظيه}

يعد التقييم البيئي الإستراتيجي من أثمل دراسات التقيم البيئي حيث أنه يمتد ليثمل كلا من الأهداف والمبادئ العامة ذات المستوى المتقدم لعمليات التقييم البيئي لدعم متخذ القرار فئي دئي توفير العديد من المعلومات والاستقراءات في مرحلة ما قبل المشروع كما يعمل على توفير

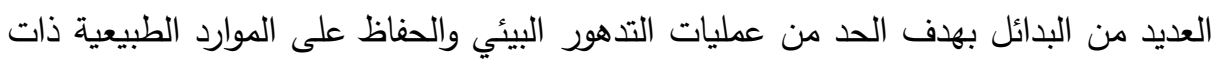
الأولوية على المستوى البيئي والإقتصادي، حيث تعد دراسات التقييم البيئي الإستراتيجي هي

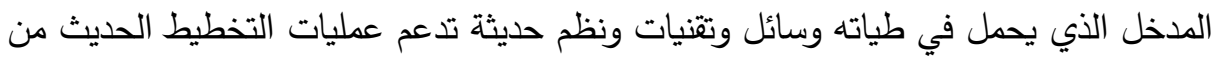

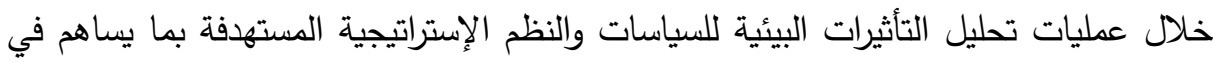
عملية صناعة القرار لتحقيق التتمية المستدامة. يعرف التقييم البيئي الإستراتيجي بتلك الدراسات الثمولية التي تتظم فى إطار علمي

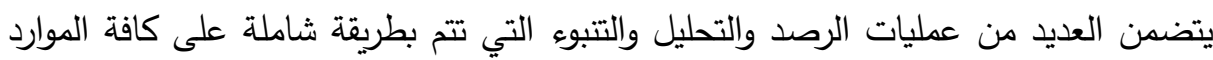
البيئية والطبيعية والبشرية والإقتصادية لتحليل التأثيرات البيئية المتوقعة للإستراتيجيات التتموية لبطية

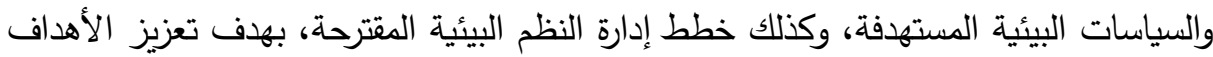
الإستراتيجية والمبادئ العليا من عملية التيقيم البيئي ودعم إتخاذ القرار. يمثل التقييم الإستراتيجي منهج علمي إستباقي شمولي على مستوى السياسات والإستراتيجيات وكافة الإعتبارات لخطط الإدارة البيئية بطريقة متكاملة على المستويات العليا

$$
\begin{aligned}
& \text { r. . . المجلد التاسع والأربعون، العدد التاسع، الجزء السابع، سبتمبر }
\end{aligned}
$$

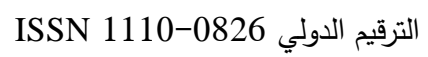




$$
\begin{aligned}
& \text { مجلة العلوم البيئية } \\
& \text { معهد الدراسات والبحوث البيئية - جامعة عين شمس له } \\
& \text { أحمد منير بهي الدين وآخرون }
\end{aligned}
$$

لاعم صناعة القرار كما أنه يتميز بالمرونة وقابل للتغذية بثكل مستمر من خلال المتغيرات

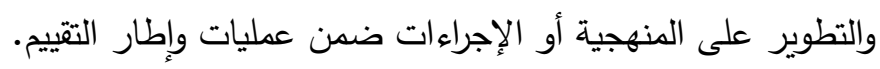

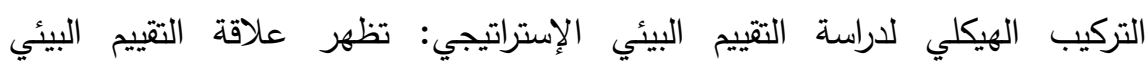
الإستراتيجي مع صناعة إتخاذ القرارمن خلال أساليب ومنهجيات علمية للتقييم تشتمل على الإنئي العديد من العمليات المتعددة ذات مراحل تطبيقية متكاملة ومتعاقبة تثمل العديد من السياسات والإستراتيجيات والخطط والبرامج التنفيذية وفقا لإستراتيجية التتمية العامة بما يتوافئه المعايير البيئية 14001 ISO ونظم الإدارة البيئية (EMS).

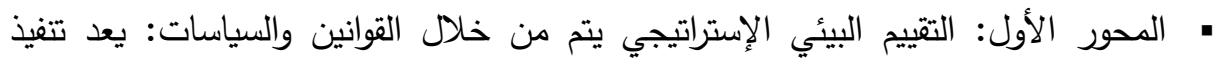

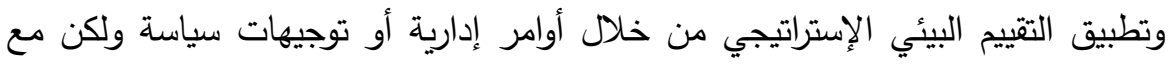
إنتشار التقييم البيئي الإستراتيجي في الكثير من الدول لها له من مكانه علمية كمنهجية شاملة تدعم صناعة إتخاذ القرار .

ومع إختلاف منهجيات التطبيق والتتفيذ أقرت بعض الدول تشريع تقييم التأثير البيئي

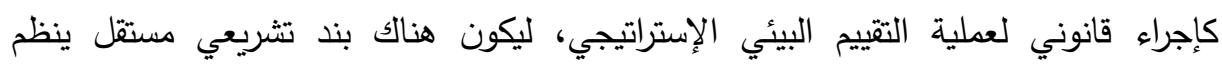

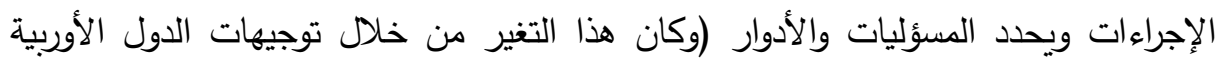
لحيز التتفيذ) حيث أن هناك العديد من أساليب ومنهجيات تتفيذ التتييم البيئي الإستراتيجي من التئن

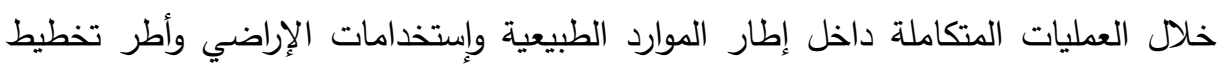
التنمية البيئية. • المحور الثاني: دعم صناعة القرار وتغطية لمقترحات سياسات التتمية ومسودة التشريع: يدعم التقييم البيئي الإستراتيجي صناعة إتخاذ القرار من خلال مستوى السياسات التي

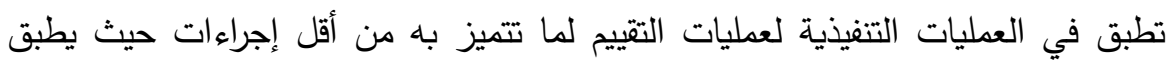
التشريع بصفة محددة أو بصورة ضمنية إلى السياسات الخاصة بالتتمية البيئية المستدامة. 


$$
\begin{aligned}
& \text { مجلة العلوم البيئية } \\
& \text { معهد الدراسات والبحوث البيئية - جامعة عين شمس لئس } \\
& \text { أحمد منير بهي الدين وآخرون }
\end{aligned}
$$

• المحور الثالث: بناء خطة التقييم البيئي الإستراتيجي على عمليات التقييم البيئي وإجراءاته: يمكن تحديد القطاعات الخاضعة لعمليات التقيم البيئي من خلال تعريفها او إدراجها بقوائم خاصة مثل الخطط والبرامج الخاصة بمشروعات التتمية، النظم البيئية التي أساسها التقييم البيئي وتعتبر ذات صلة وثيقة مع تطبيقها كجزء تكراري تكاملى ضمن خطة متكاملة بدلا' من أن تكون إجراءات مستقلة.

• المحور الرابع: التثييم البيئي الإستراتيجي إطار علمي بدرجة أكثر شمولية وتفاعلية من تقييم الأثر البيئي: يعد التقييم البيئي الإستراتيجي إطار علمي شامل يضم العيتي العديد من

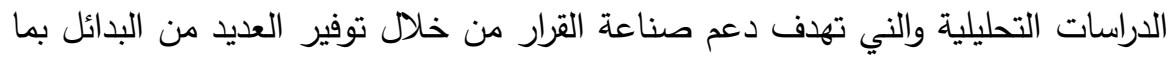
تتضمن عمليات التخطيط المكاني وإعداد الخطط البيئية الوطنية التي تهدف إلى التتمية البيئية المستدامة ودعم إستراتيجيات التتمية المستهدفة ، بينما يهتم تقييم الأثر البيئي بالتتبوء بالآثار البيئية (السلبية/الإيجابية) مع الأخذ في الإعتبار خلال مراحل عمر تتفيذ

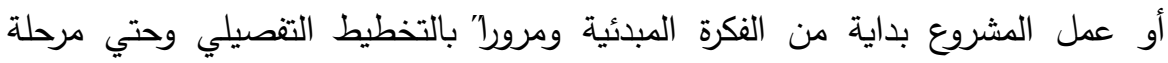

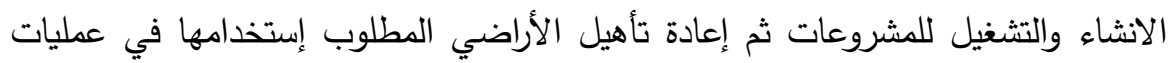
التتمية المستهدفة.

\section{الإجراعايت المنهجية اللهشيث}

أعتمد البحث على إستخدام المنهج الوصفي من خلال إستخدام نموذج شامل يراعى

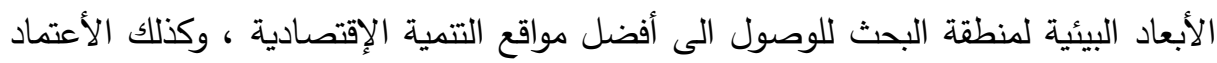

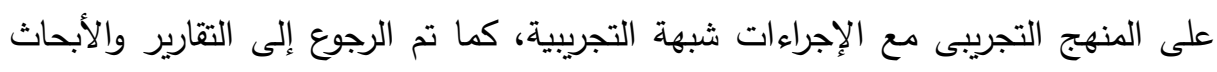

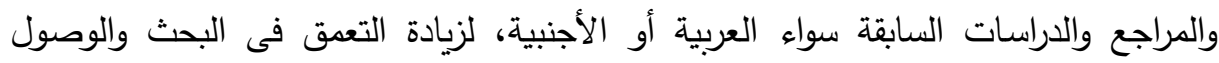


ا. إستخدام عمليات التحول الرقمي (Digital Transformation) بهدف التوصل إلى البيانات الرقمية للمعالم الجغرافية المختلفة في منطقة البحث وكذلك نمذجة المعايير والمحددات البيئية من خلال إستخدام تقنيات نظم المعلومات الجغرافية في تصميم خارطة

$$
\text { الأساس لإستخدامات الأراضي الحالية شكل( (1). }
$$

r. إستخدام تقنيات الأستشعار من البعد والعديد من مرئيات الاقمار الصناعية المتعاقبة لرصد الارصد

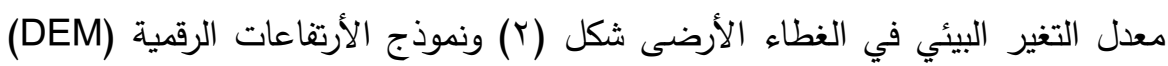

$$
\text { شكل (r)، والنموذج الرقمي شكل (ع ). }
$$

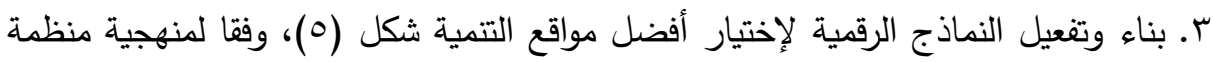
FAO ومعايير ملائمة الأراضي للتتمية المستهدفة من خلال إستخدام أسلوب التقييم • الإقليمي (Regional Assessment)

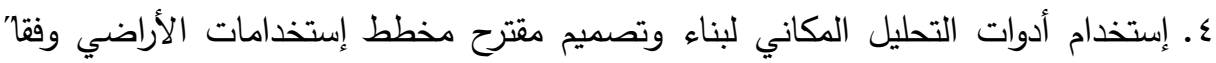
لملائمة الأراضي لطبيعة المشروعات المستهدفة،بما يتوافق مع الأشتراطات ومواصفات

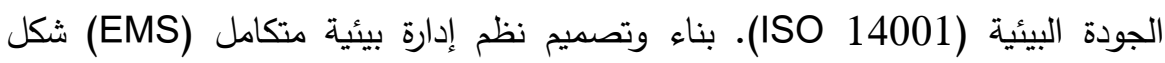

ه. دراسة التقييم البيئي الإستراتيجي كدراسة بيئية وفقا لأهداف نظم الأدارة البيئية جدول (1). 7. أستخدام أسلوب المصفوفات (Matrices) لتقييم الأثر البيئي والموازنة بين البدائل البئل المقترحة (البديل الاقتصادي/ بديل التتمية المستدامة/ البديل البيئي) كأسلوب تحليل بيئي للتتبوء بالآثار المتوقعة من المشروعات التتومية المستهدفة جدول (Y). V. إستخدام أسلوب التحليل الرباعي (SWOT Analysis) بهدف تقييم بديل التنمية المستدامة المقترح وتحليل كلا"من (نقاط القوة/ الضعف/ الفرص/ التهديدات) جدول (ץ).

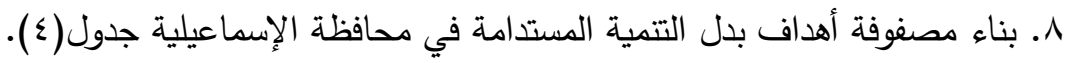




$$
\begin{aligned}
& \text { مجلة العلوم البيئية } \\
& \text { معهد الدراسات والبحوث البيئية - جامعة عين شمس له } \\
& \text { أحمد منير بهي الدين وآخرون }
\end{aligned}
$$

9 . تحليل النتائج المتوقعة وتوصيف التكامل بين المدخلات من بيانات بيئية للموارد الطبيعية،

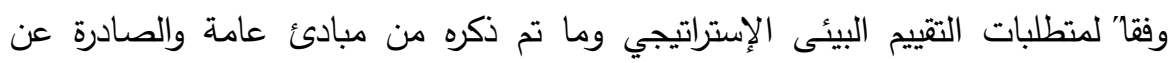

$$
\text { الجمعية الدولية لتقييم التأثير (IAIA). }
$$

• 1. استخدام مداخل التقييم للأنظمة البيئية (Eco System Approach) لتحديد طبيعة

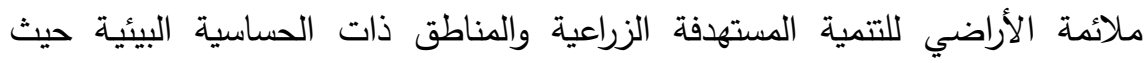
أظهرت نتائج النماذج الرقمية تصنيف ملائمة الأراضي الزراعية لبديل التتمية المستدامة كأعلى نشاط إقتصادي تتموي مقترح جدول (0)،(؟).

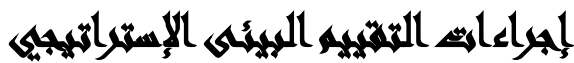

جدول (1): مصفوفة الأهداف العامة لنظم الإدارة البيئية (EMS) لإستراتيجيات التنمية

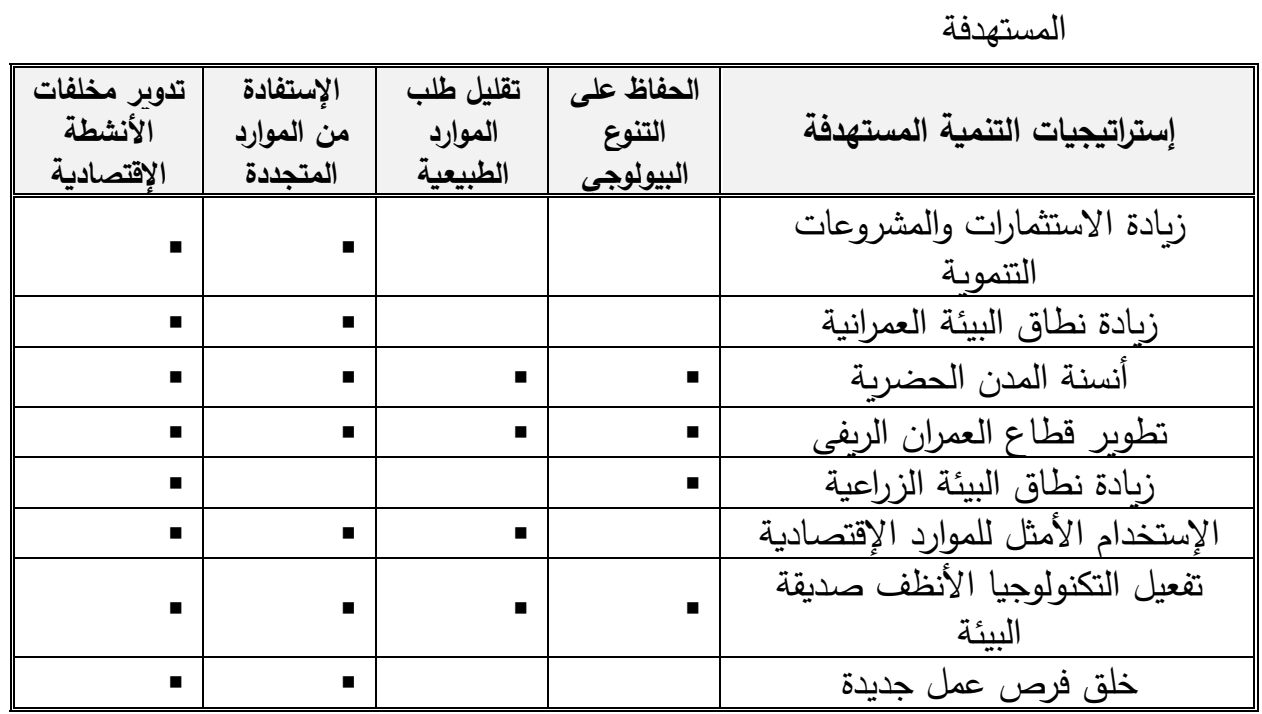

$$
\begin{gathered}
\text { المجلد التاسع والأربعون، العدد التاسع، الجزء السابع، سبتمبر · ب. الترقيم الدولي 0826- } \\
\text { ISSN 1110 }
\end{gathered}
$$


مجلة العلوم البيئية

معهد الدراسات والبحوث البيئية - جامعة عين شمس لئس

أحمد منير بهي الدين وآخرون

جدول (Y): مصفوفة الموازنة بين البدائل فى عملية التقييم البيئي

\begin{tabular}{|c|c|c|c|c|}
\hline البيئي & التبتدية & الاقتصادي البديل & وسـائل التقييم البيئـى & المخاطر \\
\hline$\checkmark$ & $\checkmark$ & $\mathbf{x}$ & تغدق التربة & \multirow{10}{*}{$\begin{array}{l}E \\
\underline{E} \\
\underline{E} \\
\underline{E}\end{array}$} \\
\hline$\Delta$ & $\checkmark$ & $\mathrm{x}$ & نوعية التربة و تواجد الأراضي الرطبة واللبخات & \\
\hline$\Delta$ & $\Delta$ & $\mathbf{x}$ & إرتقاع منسوب المياه الجوفية & \\
\hline$\Delta$ & $\checkmark$ & $\mathrm{x}$ & بحيرة التمساح & \\
\hline$\Delta$ & $\checkmark$ & $\mathbf{x}$ & 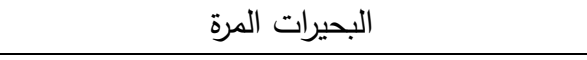 & \\
\hline$\Delta$ & $\checkmark$ & $\mathbf{x}$ & ترعة الإسماعيلية & \\
\hline$\|$ & $\checkmark$ & $\mathrm{x}$ & الحياة البرية & \\
\hline$\|$ & $\checkmark$ & $\mathbf{x}$ & البيئة الطبيعية & \\
\hline$\|$ & - & $\mathrm{x}$ & الإراضى الزراعية & \\
\hline$\|$ & - & $\mathbf{x}$ & الإستزراع السمكى & \\
\hline$\Delta$ & $\checkmark$ & $\mathbf{x}$ & البيئة الساحلية والثاطئية & \multirow{3}{*}{ 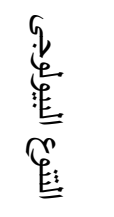 } \\
\hline$\Delta$ & $\checkmark$ & $\Delta$ & الإمتداد الطبيعى لمحميات الثمالية & \\
\hline$\checkmark$ & $\checkmark$ & $\|$ & المعالجة البيئية لكافة المشاريع الحالية & \\
\hline$\checkmark$ & - & - & إرتفاع نسبة تلوث الهواء & \multirow{3}{*}{$\begin{array}{l}\underline{E} \\
\underline{E} \\
\underline{E}\end{array}$} \\
\hline$\checkmark$ & - & - & إرتفاع نسبة تلوث التربة & \\
\hline$\checkmark$ & - & - & إرتفاع نسبة تلوث مياه المسطحات المائية & \\
\hline $\mathbf{x}$ & $\checkmark$ & $\mathbf{x}$ & التأثير السـلبى على التراث الأثرى والثقافى & \multirow{2}{*}{ 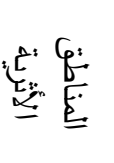 } \\
\hline - & $\checkmark$ & $\|$ & إستثمار التراث الأثرى والثقافى وتحديد حرم أثرى & \\
\hline
\end{tabular}

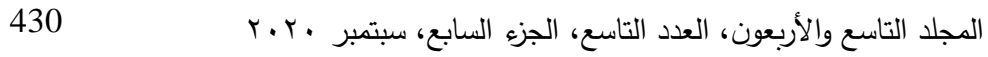

الترقيم الدولي 0826- ISSN 1110 
مجلة العلوم البيئية

معهد الدراسات والبحوث البيئة - جامعة عين شمس لإسية

أحمد منير بهي الدين وآخرون

تابع جدول (ץ): مصفوفة الموازنة بين البدائل فى عملية التقييم البيئي

\begin{tabular}{|c|c|c|c|c|}
\hline البيئيل - البيل & التنمية المستدامة & الاقتصادي البليل & وسـائل التقييم البيئـى & 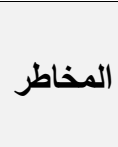 \\
\hline$x$ & $\checkmark$ & $\checkmark$ & 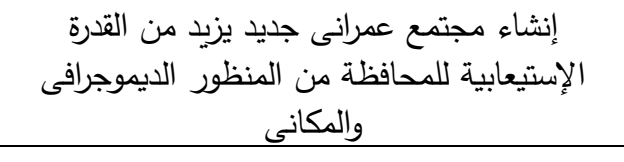 & \multirow{4}{*}{ 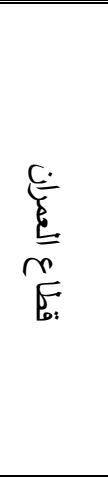 } \\
\hline $\mathbf{x}$ & $\checkmark$ & $\checkmark$ & دعم إستراتيجية تطوير وتعمير شبه جزيرة سيناء & \\
\hline $\mathbf{x}$ & $\checkmark$ & $\checkmark$ & 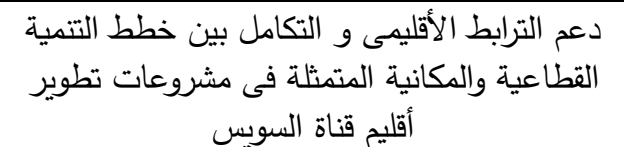 & \\
\hline $\mathbf{x}$ & $\checkmark$ & $\checkmark$ & تتمية المواقع التى ترتبط بالمشروعات القومية ذات & \\
\hline $\mathrm{x}$ & $\checkmark$ & $\mathbf{x}$ & إهدار موارد إقتصادية هامة & \multirow{8}{*}{ 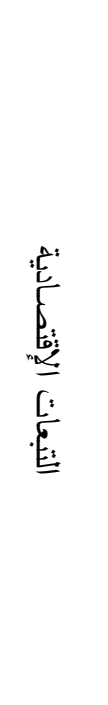 } \\
\hline$\checkmark$ & $\checkmark$ & $x$ & فقد جزء من الدخل القومى نتيجة فقد أنثطة & \\
\hline$\checkmark$ & $\mathrm{x}$ & $\mathrm{x}$ & زيادة التكاليف البيئية & \\
\hline$\|$ & $\checkmark$ & $\mathbf{x}$ & زيادة التكلفة الإقتصادية لمشروعات التتمية لمعالجة & \\
\hline $\mathrm{x}$ & $\checkmark$ & $\checkmark$ & بناء وتطوير المشروعات اللوجيستية & \\
\hline $\mathrm{x}$ & $\checkmark$ & $\checkmark$ & العائد الإقتصادى لتتفيذ مشروعات التتمية & \\
\hline$x$ & $\checkmark$ & $\checkmark$ & إتاحة التمويل البنكى اللازم لتتفيذ لتنفيذ مشروعات & \\
\hline$\checkmark$ & $\checkmark$ & $\mathrm{x}$ & الحفاظ على أراضى الإستصلاح الزراعي & \\
\hline
\end{tabular}

r. . . المجلد التاسع والأربعون، العدد التاسع، الجزء السابع، سبتمبر

الترقيم الدولي 0826- ISSN 1110 


$$
\begin{aligned}
& \text { مجلة العلوم البيئية } \\
& \text { معهد الدراسات والبحوث البيئية - جامعة عين شمس البية } \\
& \text { أحمد منير بهي الدين وآخرون }
\end{aligned}
$$

\begin{tabular}{|c|c|c|c|c|}
\hline 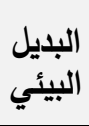 & المستدامية & الاقتصاديل & وســائل التقييم البيئى & 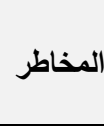 \\
\hline $\mathbf{x}$ & $\checkmark$ & $\mathbf{x}$ & التوظيف الأمثل للموارد الإقتصادية بحافظة & \multirow{4}{*}{ 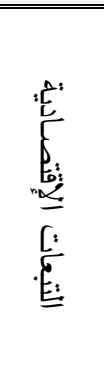 } \\
\hline $\mathbf{x}$ & $\checkmark$ & $\checkmark$ & دعم وتطويرالمشروعات المتعلقة بخدمات النقل & \\
\hline - & $\checkmark$ & $\mathrm{x}$ & تتمية وتطوير الثروة السمكية & \\
\hline घ & $\checkmark$ & $\checkmark$ & إستثمار وتتمية السياحة الداخلية فى الددى القصير & \\
\hline घ & $\checkmark$ & - & وتطوير الأماكن الثاطئية الحالية داخل الكتلة & \multirow{3}{*}{$\hat{b}^{*}$} \\
\hline - & $\checkmark$ & $\mathrm{x}$ & دمم وتطويرنشاط السياحة البيئية & \\
\hline घ & $\checkmark$ & $\|$ & 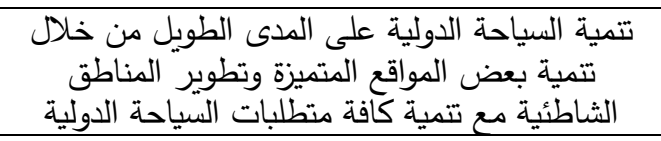 & \\
\hline$\|$ & $\checkmark$ & $\checkmark$ & دعم وتطوير وتوسعة مجرى قلإنتاة السويس وفقا & \multirow{3}{*}{$\frac{\mathfrak{E}}{\stackrel{E}{\xi}}$} \\
\hline$\|$ & $\checkmark$ & $\checkmark$ & خلق محور أقليمى للتتمية يربط موانئ البحر المتوسط & \\
\hline$\|$ & $\checkmark$ & $\checkmark$ & 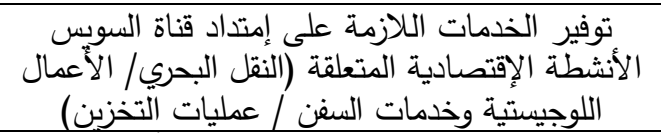 & \\
\hline \multicolumn{4}{|r|}{ 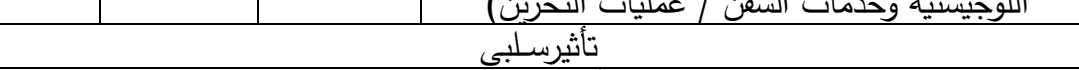 } & $\mathrm{x}$ \\
\hline \multirow{2}{*}{\multicolumn{4}{|c|}{ غيرمؤثر سلبا أو إيجابا }} & $\sqrt{ }$ \\
\hline & & & & $\Delta$ \\
\hline \multicolumn{4}{|c|}{ تأثير غير معروف ولكن متوقع } & - \\
\hline \multicolumn{4}{|c|}{ " دون بيان } & $\|$ \\
\hline
\end{tabular}

تابع جدول (ץ): مصفوفة الموازنة بين البدائل فى عملية التقييم البيئي

432

$$
\begin{aligned}
& \text { r.r. · المجلد التاسع والأربعون، العدد التاسع، الجزء السابع، سبتمبر } \\
& \text { الترقيم الدولي 0826- ISSN 1110 }
\end{aligned}
$$


جدول (ץ): التحليل الرباعي (SWOT Analysis) لبديل التتمية المستدامة المقترح

\begin{tabular}{|c|c|c|c|}
\hline \multicolumn{4}{|c|}{ العوامل الإيجابية } \\
\hline 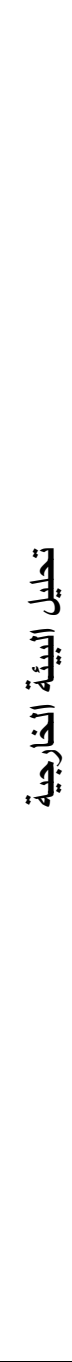 & 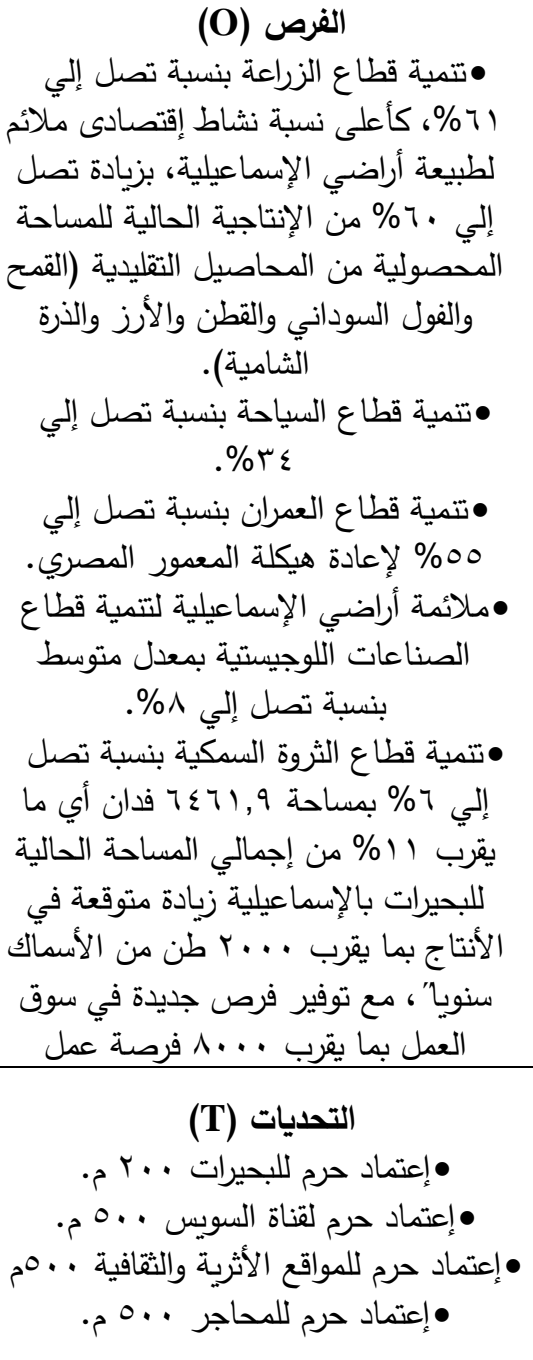 & 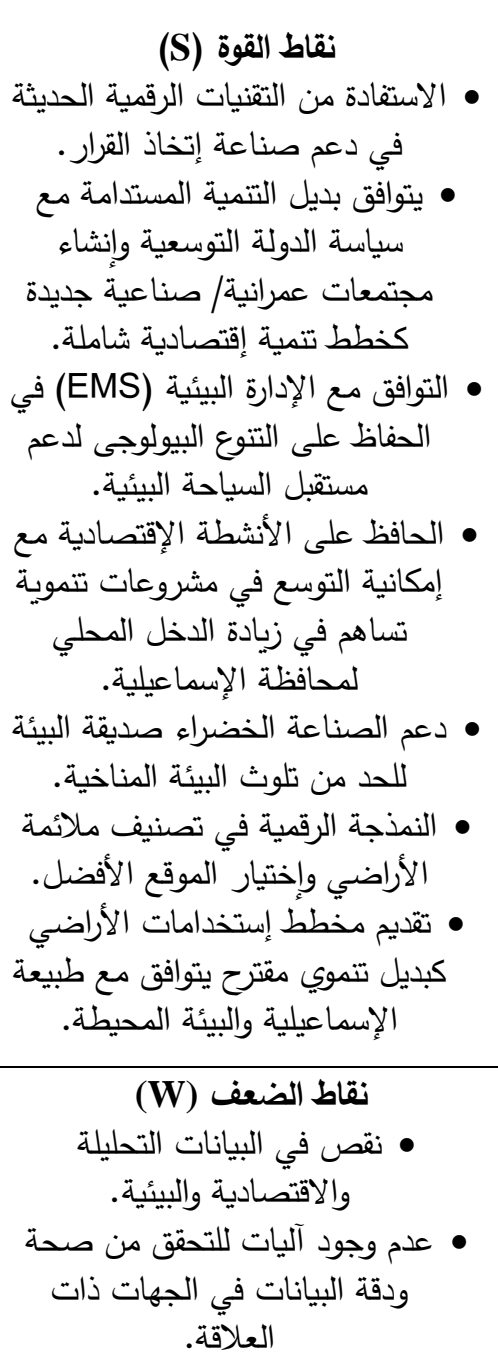 & 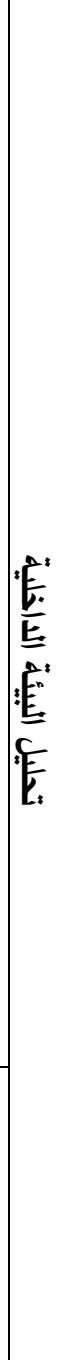 \\
\hline \multicolumn{4}{|c|}{ العوامل السلبية } \\
\hline
\end{tabular}




$$
\begin{aligned}
& \text { مجلة العلوم البيئية } \\
& \text { معهد الدراسات والبحوث البيئية - جامعة عين شمس للئس } \\
& \text { أحمد منير بهي الدين وآخرون }
\end{aligned}
$$

\begin{tabular}{|c|c|c|}
\hline \multicolumn{3}{|c|}{ جدول (ء): مصفوفة أهداف بديل التتمية البيئية المستدامة لمحافظة الإسماعيلية } \\
\hline السياسات البيئية والإجراءات المطلوبة & نظم التنمية البيئية المستدامة & الإستراتيجي \\
\hline 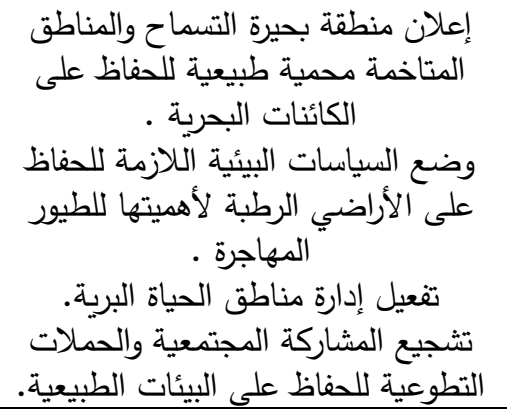 & دعم حماية البيئية والحد من الحفاظ على الحيئئ البرية. & التتوع البيولوجى على الحية البرية \\
\hline 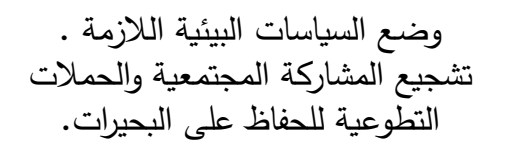 & البيئية والحفاظ الإستدامة وحماية الأصول الرواردية & التدهور البيئي \\
\hline 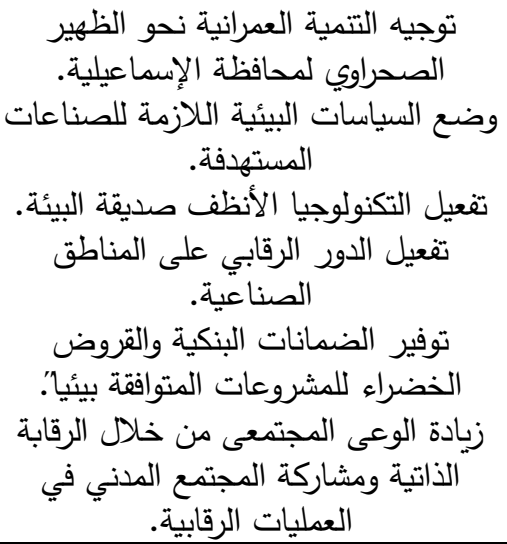 & 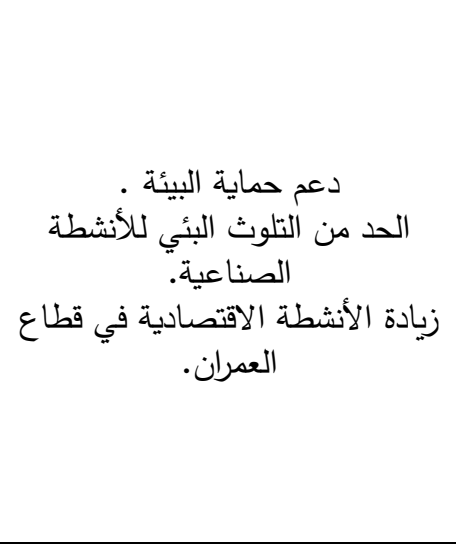 & قالمستدامة \\
\hline
\end{tabular}

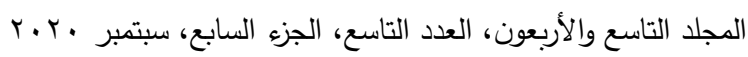

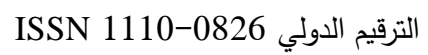




$$
\begin{aligned}
& \text { مجلة العلوم البيئية } \\
& \text { معهد الدراسات والبحوث البيئية - جامعة عين شمس لبنه } \\
& \text { أحمد منير بهي الدين وآخرون }
\end{aligned}
$$

\begin{tabular}{|c|c|c|}
\hline السياسات البيئية والإجراءات المطلوبـة & نظم التنمية البيئية المستدامة & الإستراتيجي \\
\hline 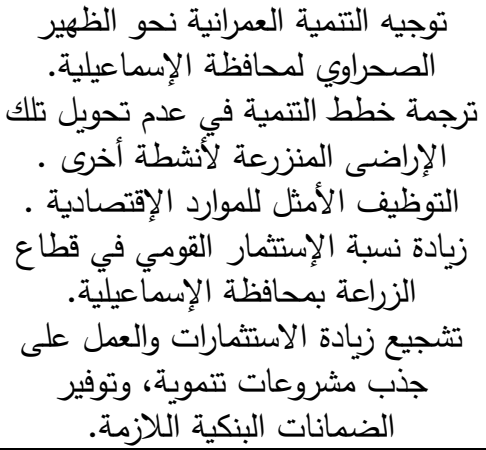 & 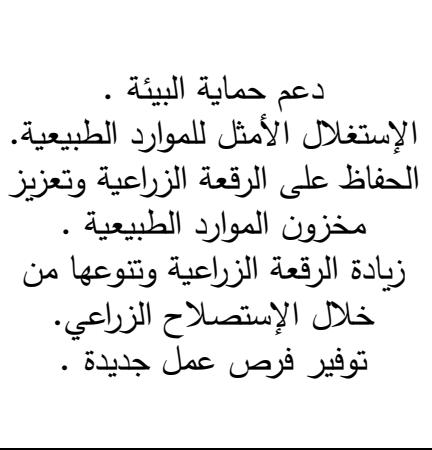 & قطاع المستدامة التزية \\
\hline 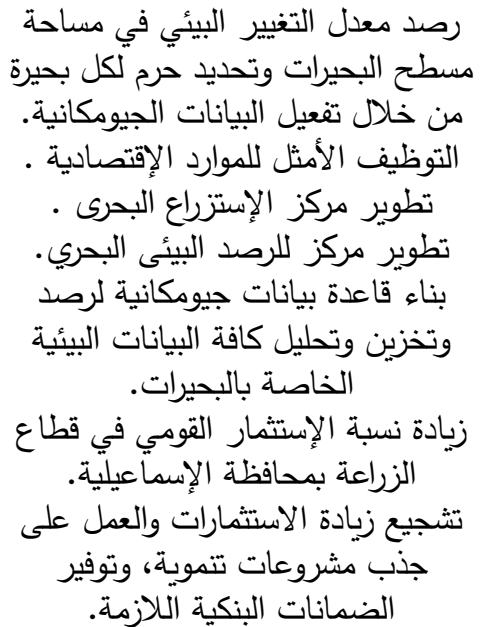 & 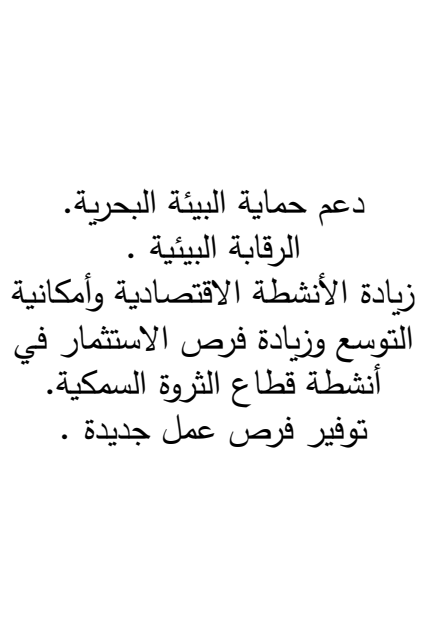 & 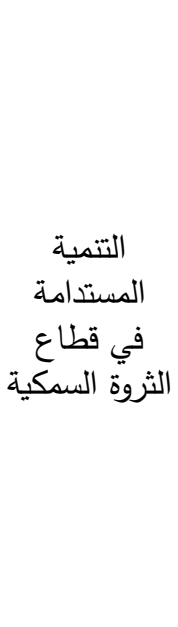 \\
\hline
\end{tabular}

تابع جدول (؛ ): مصفوفة أهداف بديل التتمية البيئية المستدامة لمحافظة الإسماعيلية

$$
\begin{aligned}
& \text { r. r. • المجلد التاسع والأربعون، العدد التاسع، الجزء السابع، سبتمبر } \\
& \text { الترقيم الدولي 0826-0 الإنوني }
\end{aligned}
$$




$$
\begin{aligned}
& \text { مجلة العلوم البيئية } \\
& \text { معهد الدراسات والبحوث البيئية - جامعة عين شمس له } \\
& \text { أحمد منير بهي الدين وآخرون }
\end{aligned}
$$

\begin{tabular}{|c|c|c|}
\hline السياسات البيئية والإجراءات المطلوبة & نظم التنمية البيئية المستدامة & الإستراتيجي \\
\hline 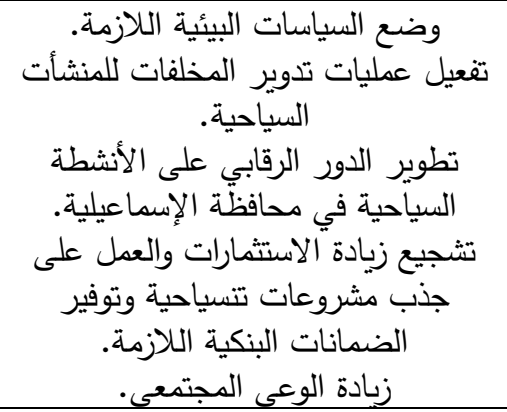 & زيادة الأنشطة الاقتصادية في البيئة البحرية . قطاع & قطاع السيآحة \\
\hline 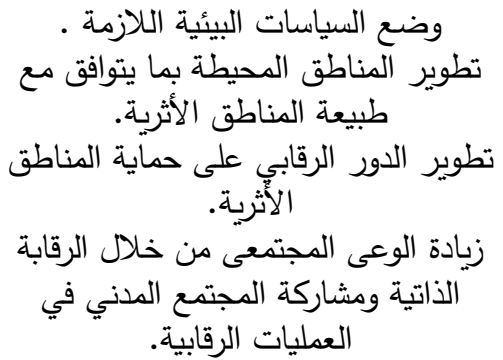 & 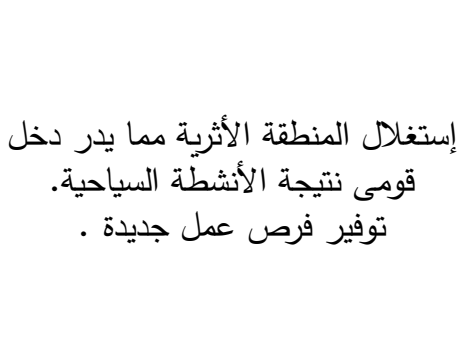 & المناطق الأثرية \\
\hline
\end{tabular}

تابع جدول (؛): مصفوفة أهداف بديل التتمية البيئية المستدامة لدحافظة الإسماعيلية

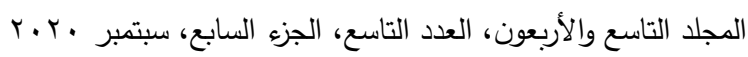

$$
\begin{aligned}
& \text { الترقيم الدولي 0826-0 الإنون، }
\end{aligned}
$$




$$
\begin{aligned}
& \text { مجلة العلوم البيئية } \\
& \text { معهد الدراسات والبحوث البيئية - جامعة عين شمس له } \\
& \text { أحمد منير بهي الدين وآخرون }
\end{aligned}
$$

\begin{tabular}{|c|c|c|c|}
\hline & \multirow{2}{*}{ تصنيف ملائمة الأراضي } & \multirow{2}{*}{ تصنيف فئات } \\
\hline$\%$ & فدان & & \\
\hline$\%$ \%r & $r \leqslant \wedge \wedge \leqslant 9,7$ & مناطق ذات ملائمة مرتفعة & الفئة الأولى (S1) \\
\hline$\%$ rq & 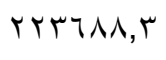 & مناطق ذات ملائمة معتدلة & الفئة الثانية (S2) \\
\hline$\%$ r & lOVYVV,0 & مناطق ذات ملائمة منخفضـة & الفئة الثالثة (S3) \\
\hline$\% \backslash \wedge$ & $\mid r \Delta \Lambda \cdot 1$ & مناطق ذات ملائمة ضعيفة & الفئة الرابعة (N1) \\
\hline
\end{tabular}

جدول (•): تصنيف ملائمة الأراضي الزراعية لبديل التتمية المستدامة كأعلى نشاط إقتصادي

\begin{tabular}{|c|c|c|c|c|c|c|}
\hline العائد الاقتصادي/ج & صافي & إجمالي إنتاجية & الفدان/طن & المساحة & \multicolumn{2}{|c|}{ الزحاصيل } \\
\hline 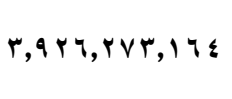 & $\Lambda, £ \cdot\{$ & $\neg \leqslant \varepsilon, \vee Y Y, \diamond \wedge$. & $1, r \wedge$. & $\leq 78,191$ & السوداني & : \\
\hline 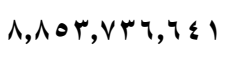 & 11901 & $v, v \cdot \Lambda, 701,0 \ldots$ & $170 \ldots$ & $\leq 78,191$ & الطماطم & $E$ \\
\hline $1, r \cdot r, \cdot \wedge r, \leq \leq r$ & Y,OVY & $1, r|\wedge, \varepsilon| r, \ldots r$ & rAYr & $\varepsilon 78,191$ & القمـح & $=\dot{E}_{z}^{2}$ \\
\hline$\Lambda \leq 0, \neg \mid 0, \vee 1$. & $1, \wedge 1$ & $1 \cdot, \cdot q r, r \diamond q, q \wedge r$ & rIT.r & $\leq 78,191$ & السكر & $\underline{E}$ \\
\hline
\end{tabular}

جدول (†): إجمالي إنتاجية المحاصيل الزراعية والعائد الاقتصادي المتوقع ضمن مقترح بديل

التمية المستدامة

$$
\begin{aligned}
& \text { r. r. • المجلد التاسع والأربعون، العدد التاسع، الجزء السابع، سبتمبر } \\
& \text { الترقيم الدولي 0826-0 الإنوني }
\end{aligned}
$$




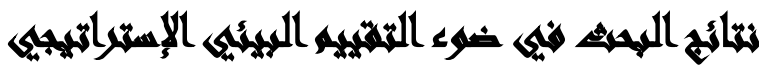

خرج البحث بالعديد من النتائج منها ما يتوافق مع نتائج دراسات سابقة، ومنها نتائج للبحث الحالي السبق في الوصول إليها والتي تم إدراجها قاعدة بيانات جيومكانية لتطبيق منهجية منظمة (FAO) في تصنيف ملائمة الأراضي للتمية المستهدفة، وتقديم مخطط التتمية المستدامة المقترح مع الحفاظ على الأنشطة الاقتصادية القائمة والإستغلال الأمثل

$$
\text { للموارد (الطبيعية/البشرية) المتاحة بالبيئة. }
$$

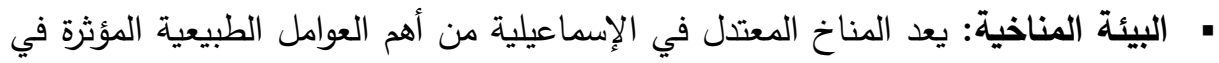

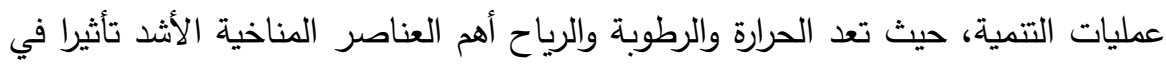
إعادة تتسيق الهيكل العمرانى فضلا عن أنشطة الصيد والسياحة الثاطئية كأنشطة

$$
\text { إقتصادية تساهم في الناتج المحلي. }
$$

• البيئة البحرية: يوجد في محافظة الإسماعيلية العديد من المسطحات المائي (قناة السوي/ بحيرة التمساح/ البحيرات المره) والتي تستخدم في العديد من أنشطة الثروة سمكية

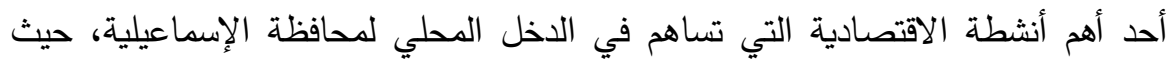

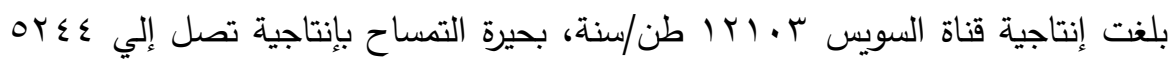

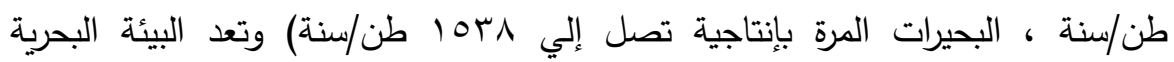

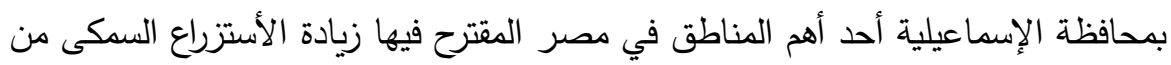

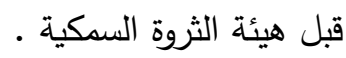
• الغطاء النباتي: تتميز الإسماعيلية بوفرة العديد من الظروف الطبيعية المؤثرة في تواجد

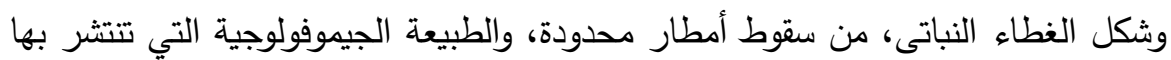
الصحاري والرمال وعدة مسطحات مائية تتنشرها في محيطها السبخات الملحية، ونسبة وندية منخفضة من تربات الأودية الجافة. وتتعكس هذه الظروف على تكوين بيئة الغطاء النباتى.

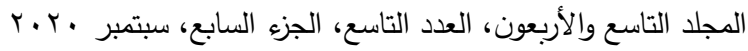

$$
\begin{aligned}
& \text { الترقيم الدولي 0826- ISSN 1110 }
\end{aligned}
$$




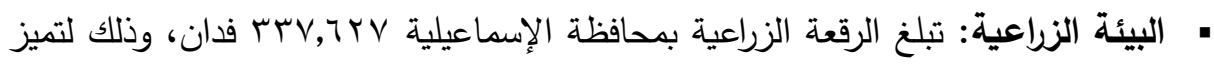

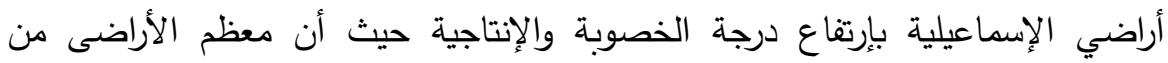

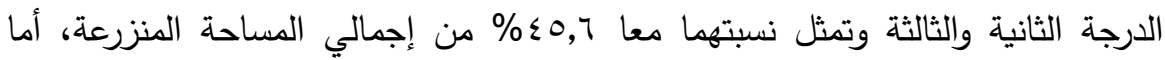

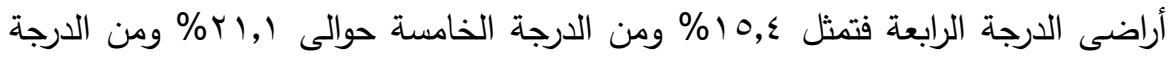

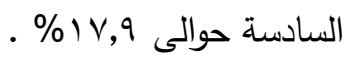
• الثروات المعدنية: تمتلك الإسماعيلية على العديد من الثروات الطبيعية كـ(رواسب الطلفلة/

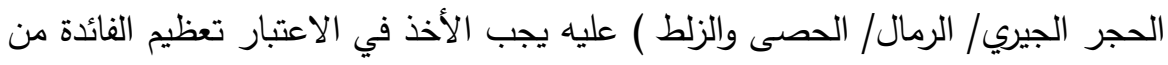
خلال الإستغلال الأمثل لتلك الموارد بما يمثل قيمة مضافة في خطط التتمية المستهدفة. • التراث الأثري والثقافي: تتواجد عدة مواقع أثرية وثقافية هامة داخل حدود الإدارية لمحافظة

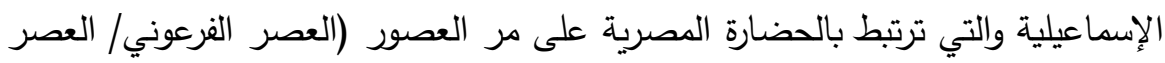

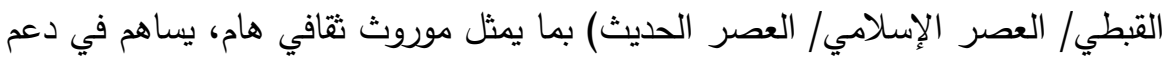

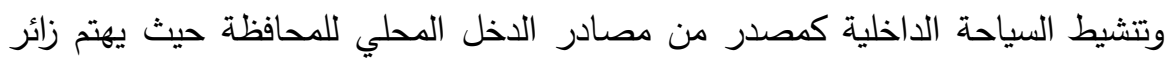
الإسماعيليلة بزيارتها والتعرف عليها. • زيادة الحمل البيئسى بمنطقة البحث: تعد محافظة الإسماعيلية إمتداد الطبيعى لأرضي

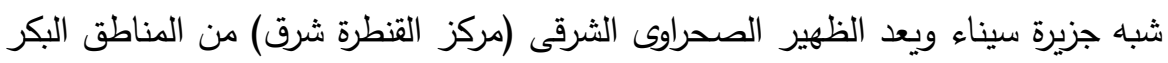

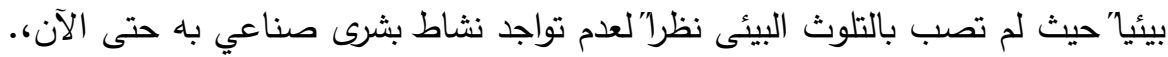

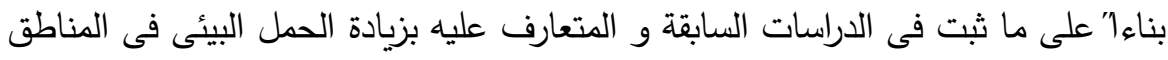

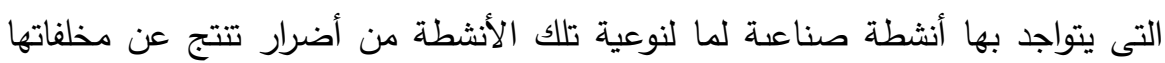
سواء كانت فى حالتها الغازية أو السائلة أو الصلبة.

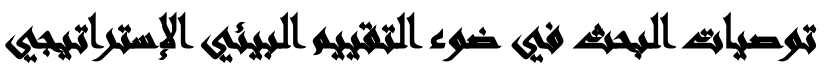

$$
\begin{aligned}
& \text { r. . . المجلد التاسع والأربعون، العدد التاسع، الجزء السابع، سبتمبر }
\end{aligned}
$$

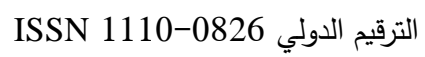




$$
\begin{aligned}
& \text { مجلة العلوم البيئية } \\
& \text { معهد الدراسات والبحوث البيئية - جامعة عين شمس لبس } \\
& \text { أحمد منير بهي الدين وآخرون }
\end{aligned}
$$

يوصى البحث بضرورة إستغلال الموقع الجغرافى المتميز لمحافظة الإسماعيلية من خلال

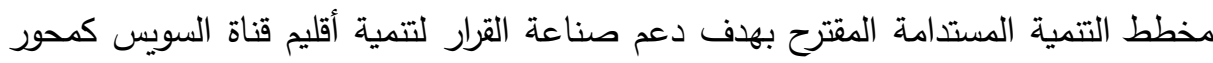

$$
\text { هام للتتمية مع ضرورة مراعاة المواصفات الجيوبيئية. }
$$

ا. الإستغلال الأمثل للموارد الإقتصادية المتاحة بمحافظة الإسماعيلية إعتمادا على الميزة

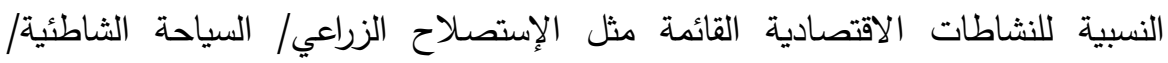

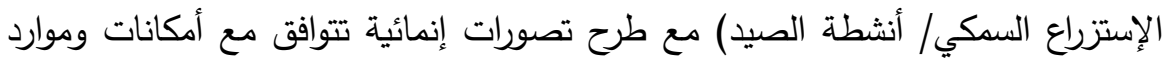

$$
\text { البيئات المحيطة. }
$$

r. إعلان منطقة (بحيرة التمساح) محمية طبيعيه لما لها من خصائص بيئية تساهم في

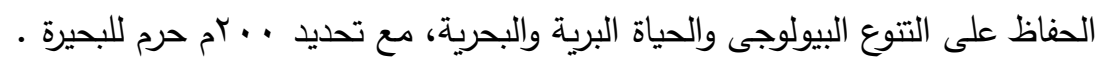

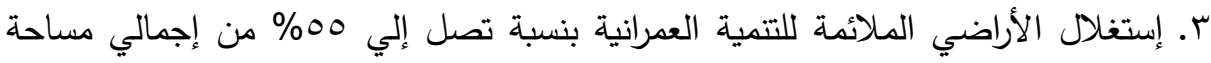
المخطط المقترح للتمية كنشاط تتموي هام لما تمتلكه تلك الأراضي من مقومات متوافقه إلهاته

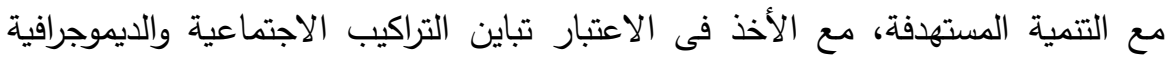

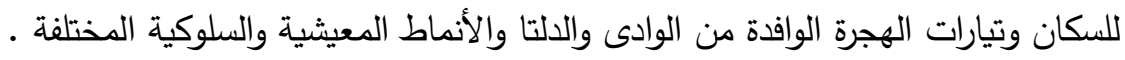

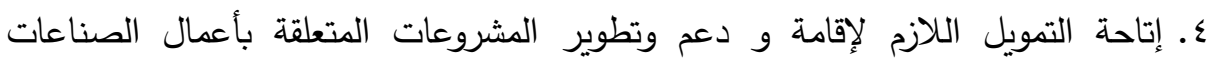

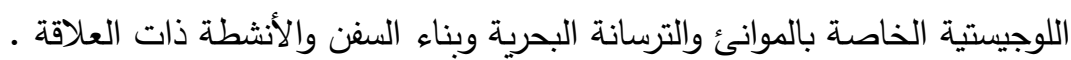

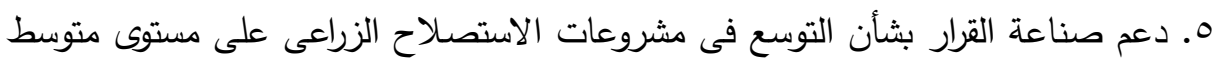

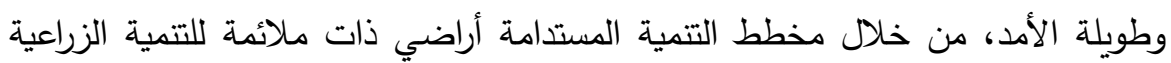
بنسبة تصل إلي ع , آ7\% من إجمالي مساحة المخطط كأعلى نشاط إقتصادى ملائم. 7. إمكانية تنمية وتطوير قطاع الثروة السمكية بتخصيص أراضي ذاتية إت ملائمة لأنشطة الثروة

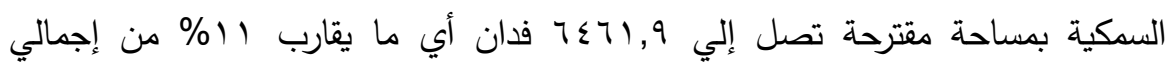
المساحة الحالية للبحيرات (0V7/O فدان) مما يؤدى إلي زيادة متوقعة في الأنتاج بما

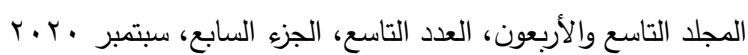

$$
\begin{aligned}
& \text { الترقيم الدولي 0826-0 1110 }
\end{aligned}
$$




$$
\begin{aligned}
& \text { مجلة العلوم البيئية } \\
& \text { معهد الدراسات والبحوث البيئية - جامعة عين شمس له } \\
& \text { أحمد منير بهي الدين وآخرون هابله }
\end{aligned}
$$

يقرب . . . . ط طن من الأسماك سنوياً، مع توفير فرص في سوق العمل بما يقارب .. . فرصة عمل. V. دراسة وتنفيذ مقترح سبل لتمية قطاع السياحة الثقافية والأثرية مع توفير أراضي ذات ملائمة بنسبة ع, •. من إجمالي مساحة المخطط المقترح مما يدر دخل محلى لمحافظة

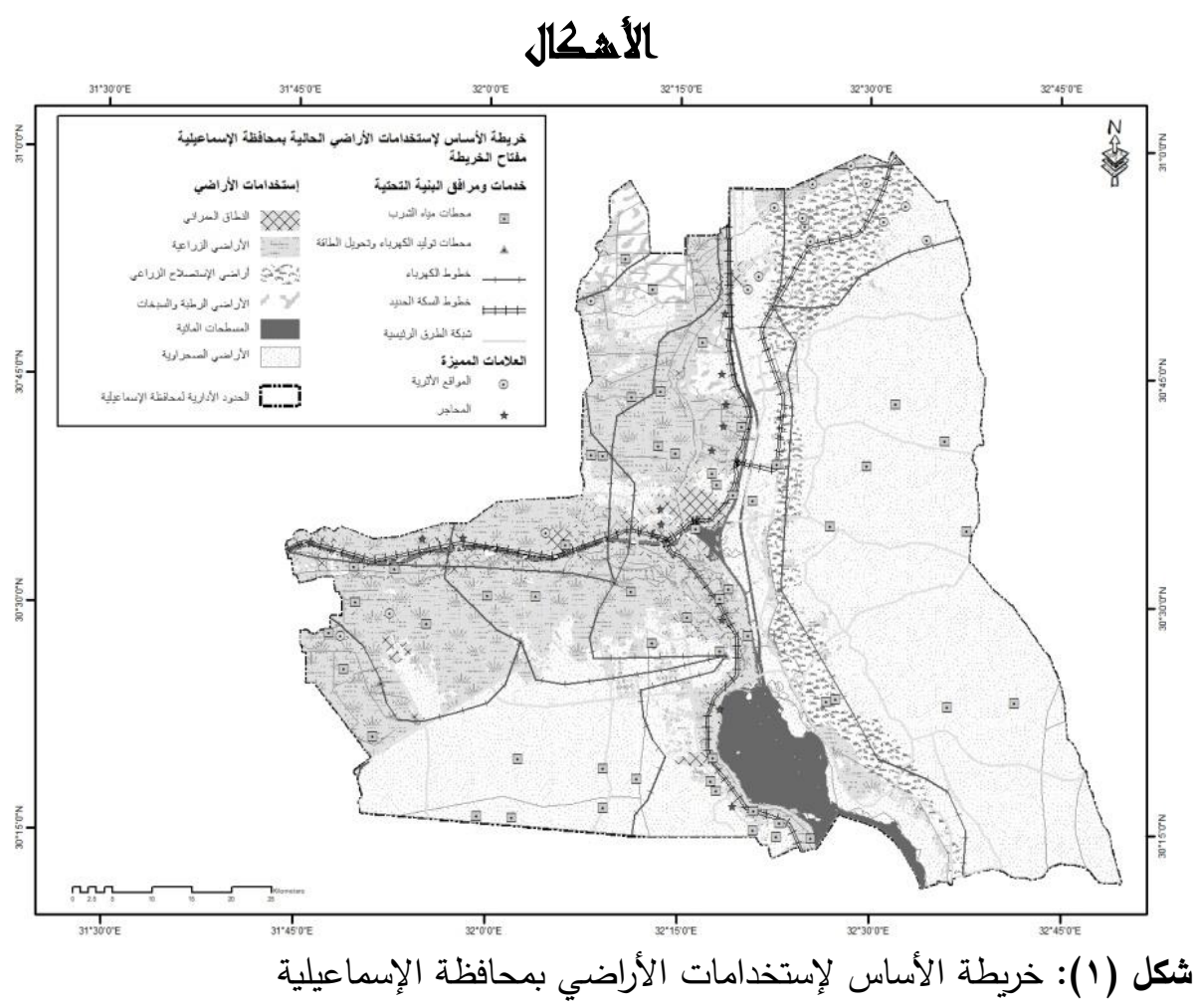

$$
\begin{gathered}
\text { المجلد التاسع والأربعون، العدد التاسع، الجزء السابع، سبتمبر · . الترقيم الدولي 0826-0 } \\
\text { ISSN 1110 }
\end{gathered}
$$




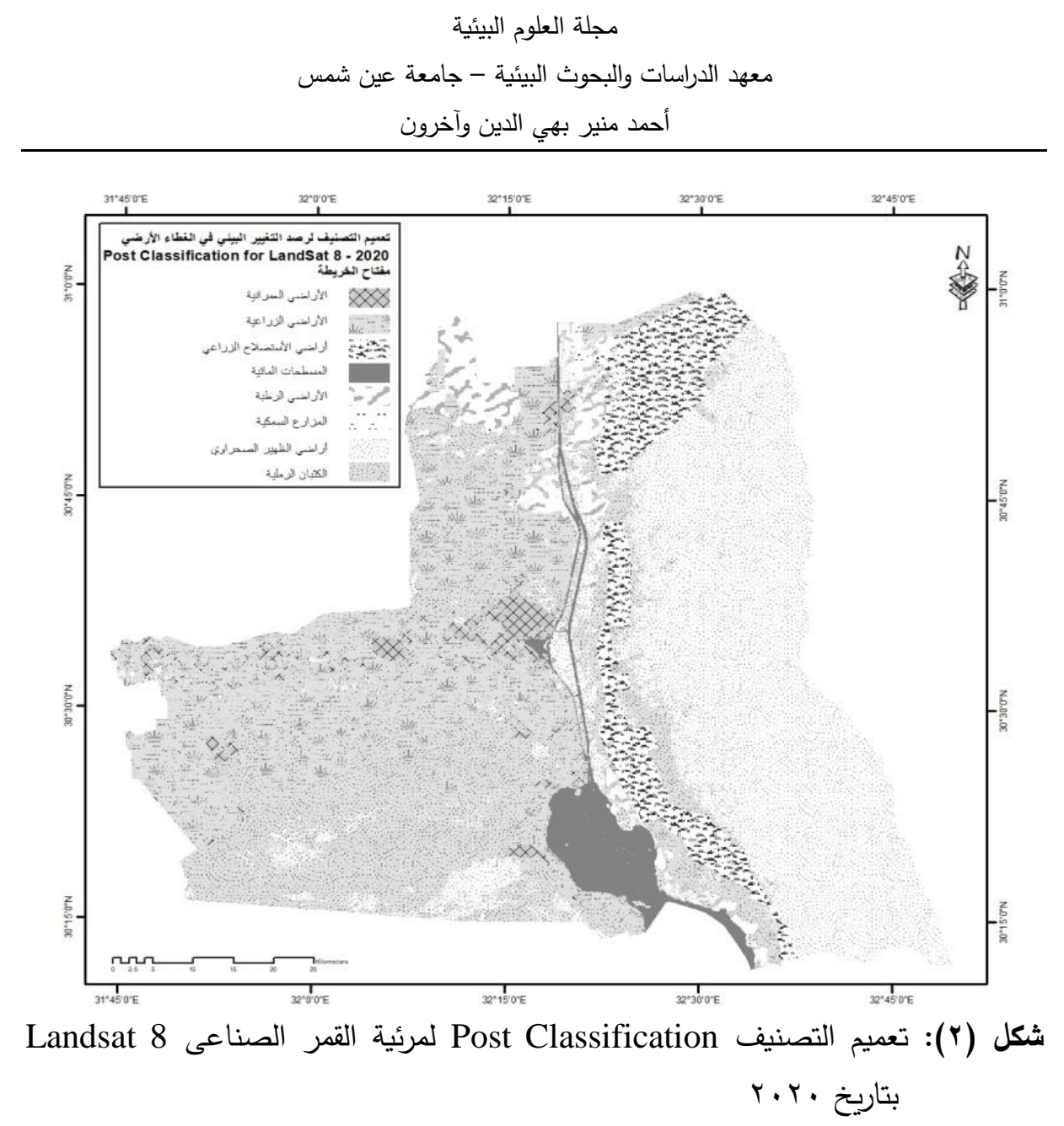

442

$$
\begin{aligned}
& \text { r. r. • المجلد التاسع والأربعون، العدد التاسع، الجزء السابع، سبتمبر }
\end{aligned}
$$

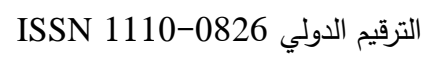


مجلة العلوم البيئية

معهد الدراسات والبحوث البيئية - جامعة عين شمس له

أحمد منير بهي الدين وآخرون

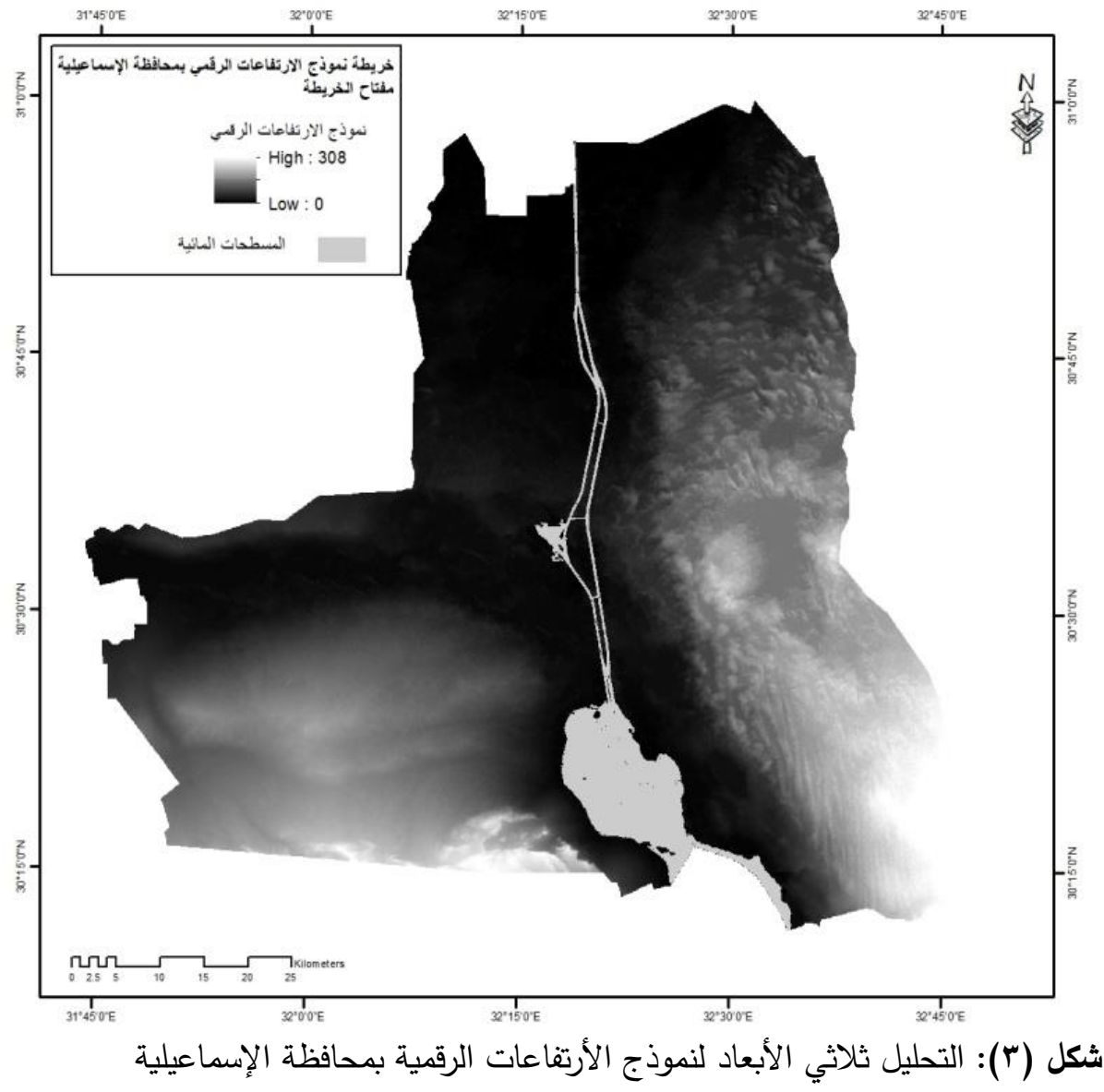

r. r. • المجلد التاسع والأبعون، العدد التاسع، الجزء السابع، سبتمبر

الترقيم الدولي 0826-0 التونون 

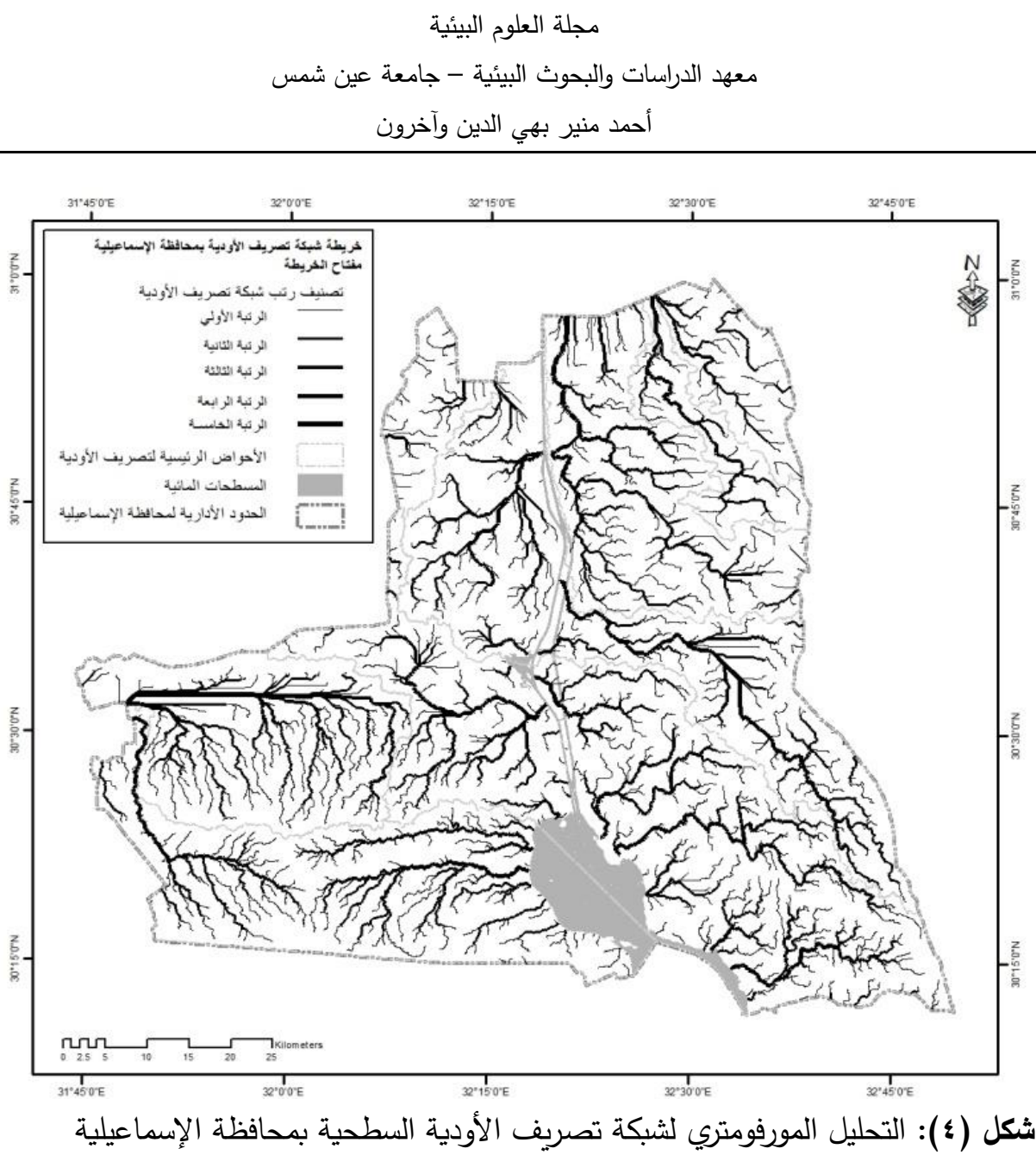

$$
\begin{aligned}
& \text { r. r. • المجلد التاسع والأربعون، العدد التاسع، الجزء السابع، سبتمبر }
\end{aligned}
$$

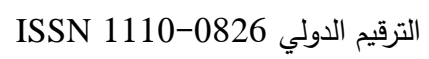




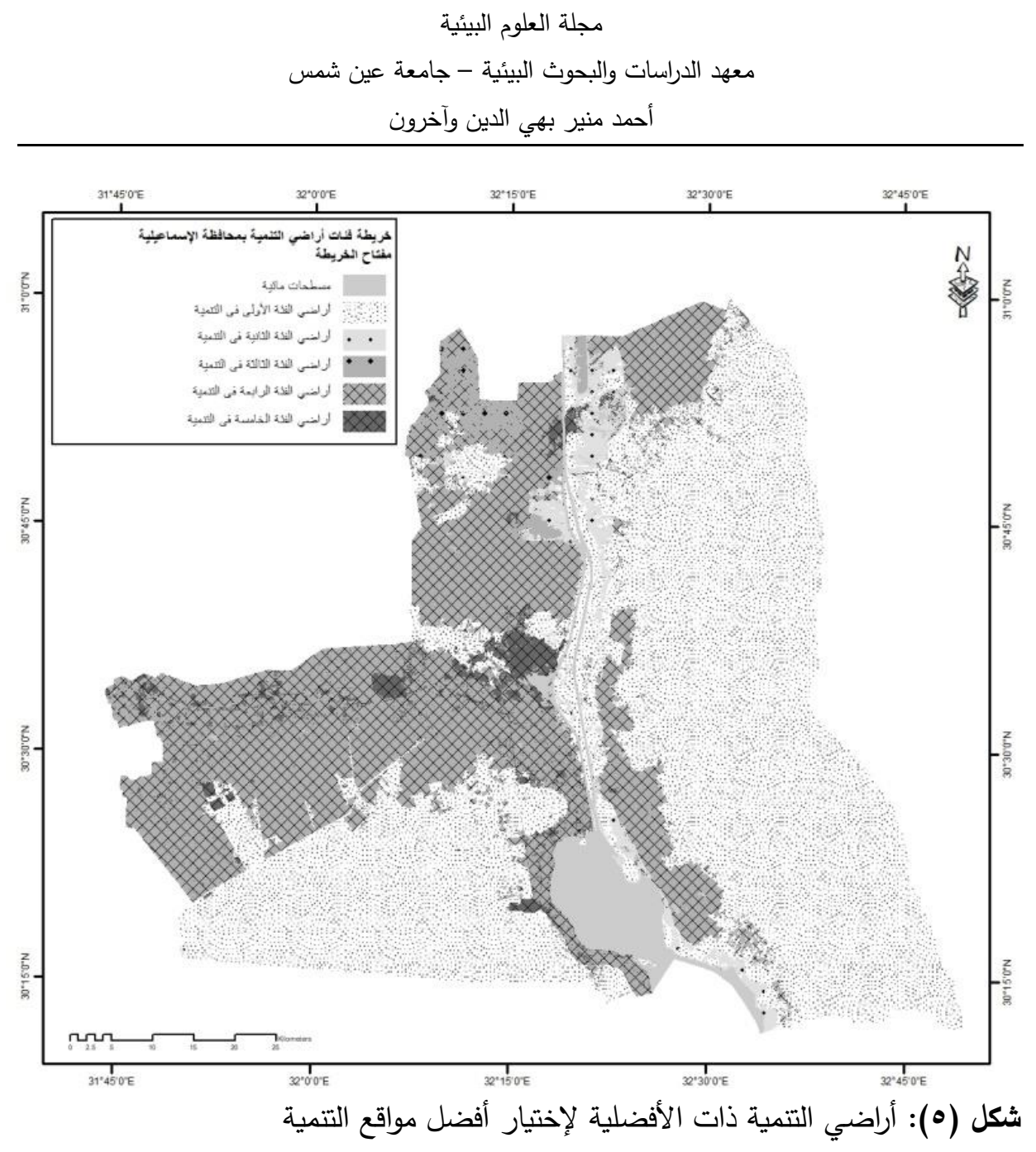

$$
\begin{aligned}
& \text { r. r. • المجلد التاسع والأربعون، العدد التاسع، الجزء السابع، سبتمبر } \\
& \text { الترقيم الدولي 0826-0 الارعون، }
\end{aligned}
$$




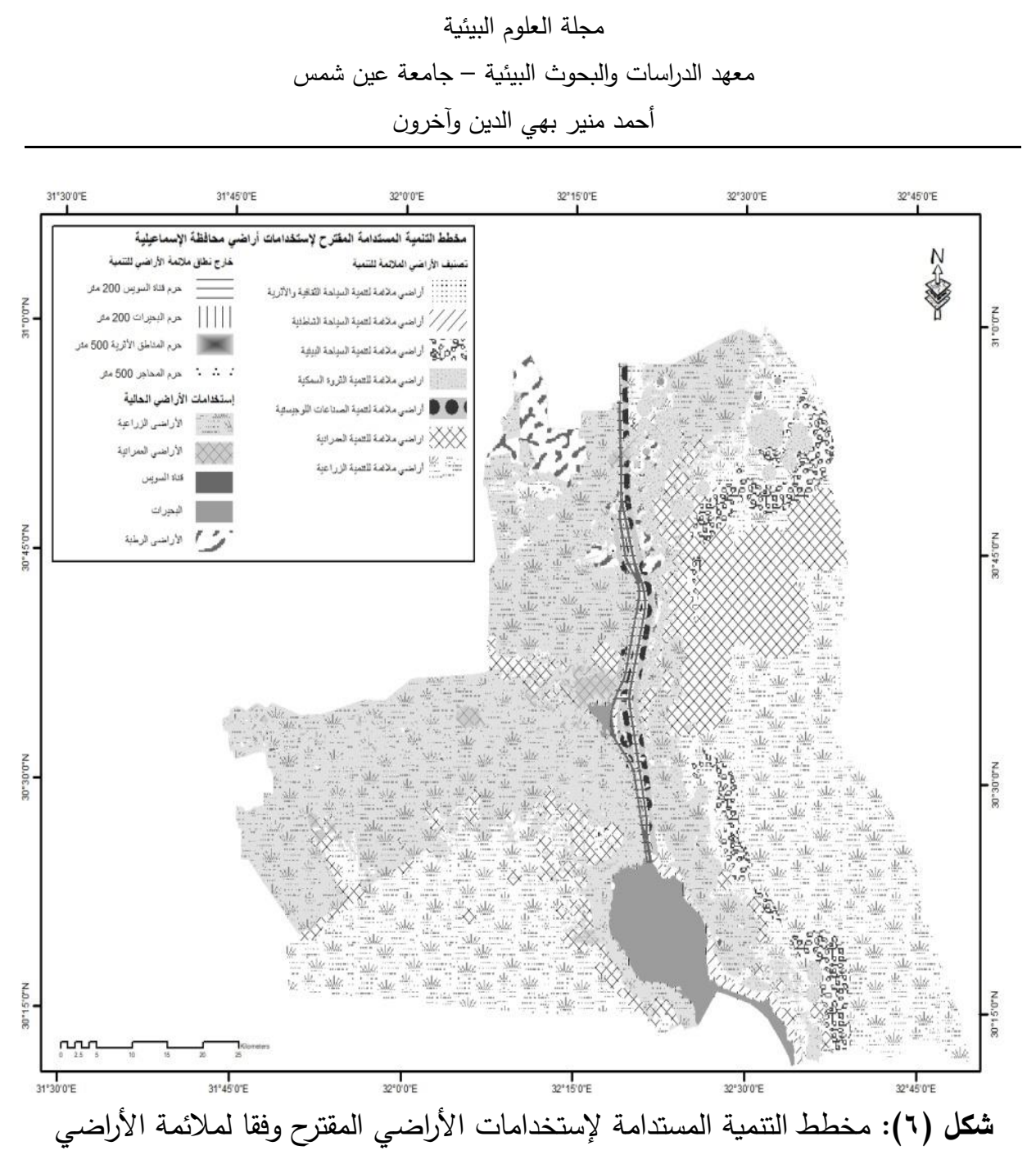

446

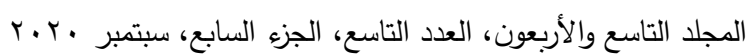

$$
\begin{aligned}
& \text { الترقيم الدولي 0826- ISSN 1110 }
\end{aligned}
$$


مجلة العلوم البيئية

معهد الدراسات والبحوث البيئية - جامعة عين شمس له

أحمد منير بهي الدين وآخرون

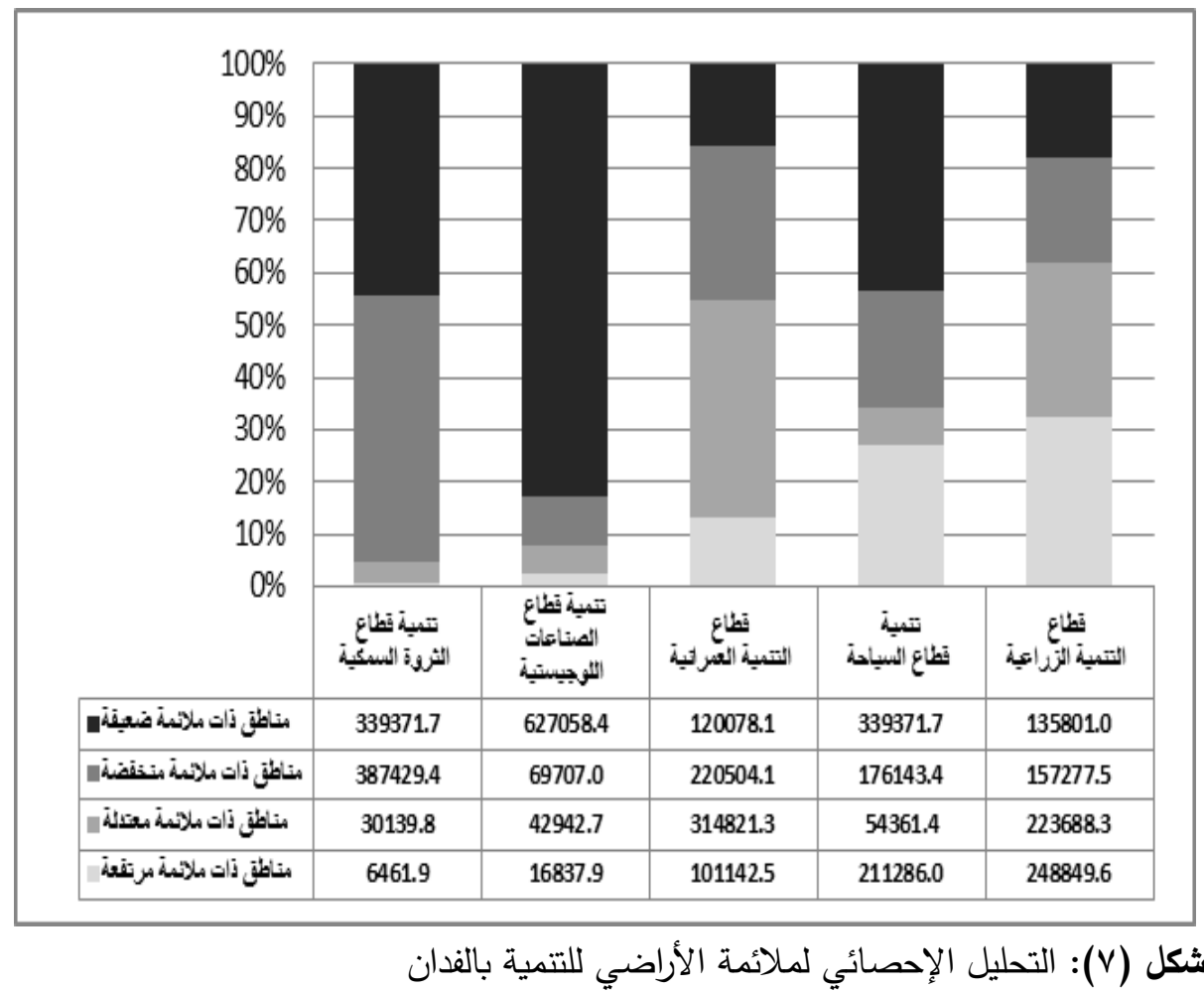

\section{المرأيt}

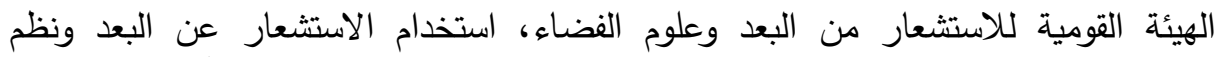

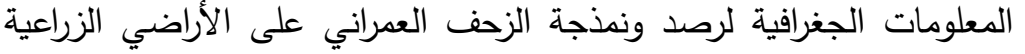

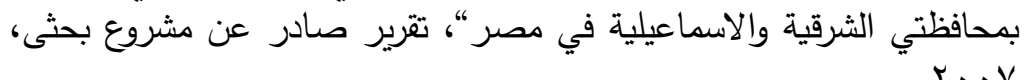

$$
\begin{aligned}
& \text { r.r. المجلد التاسع والأربعون، العدد التاسع، الجزء السابع، سبتمبر } \\
& \text { الترقيم الدولي 0826- ISSN 1110 }
\end{aligned}
$$




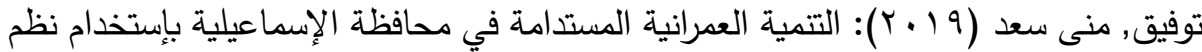

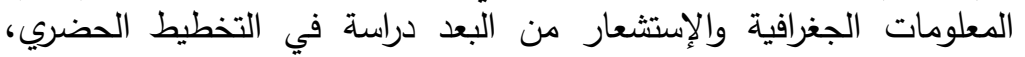

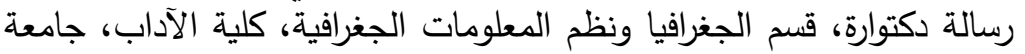

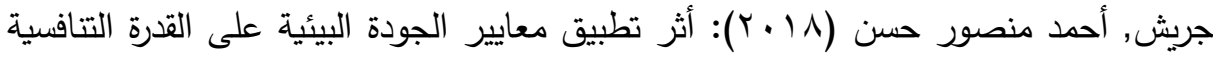

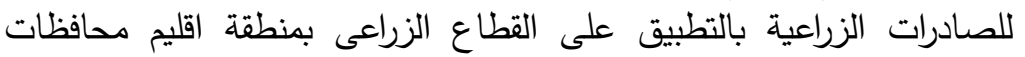
القناة، رسالة دكتوراه الفلسفة في العلوم البيئية، معهد الدراسات والبـاتئية البحوث البيئية،

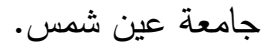

عبد الفتاح, أميرة صالح (9 . . ب): السياحة في محافظة الإسماعيلية، رسالة ماجيستير، كلية

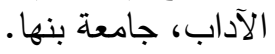

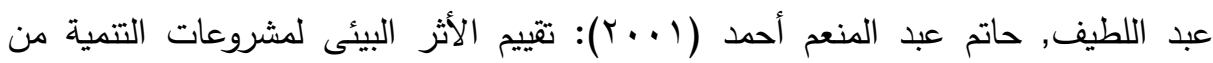

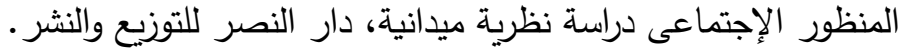

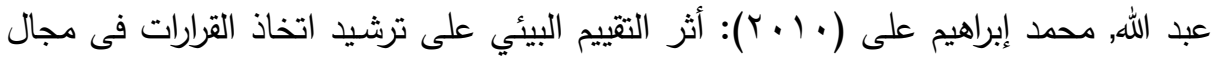
حماية البيئة من التلوث، رسالة دكتوراه، معهد الدراسات والبئية البحوث البيأئية،

$$
\text { جامعة عين شمس. }
$$

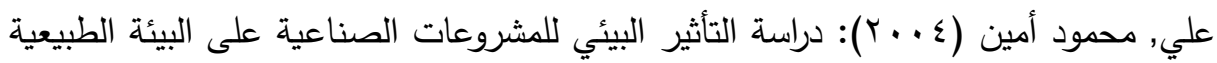

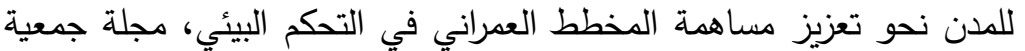

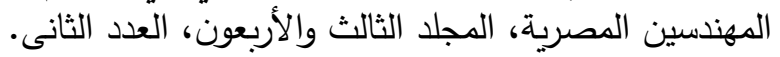

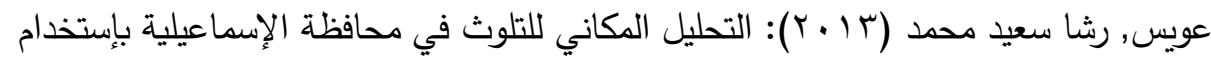

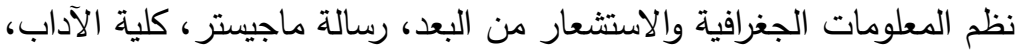

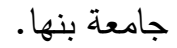

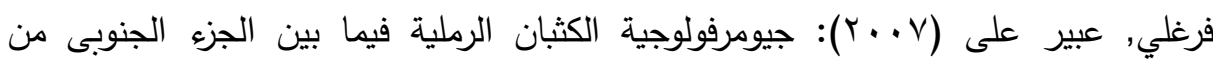

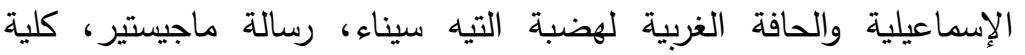

$$
\text { الاداب، جامعة الأسكندرية. }
$$

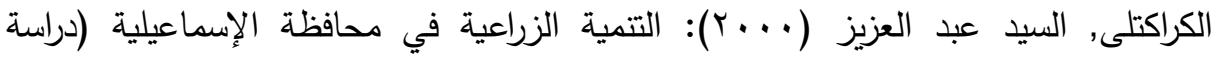

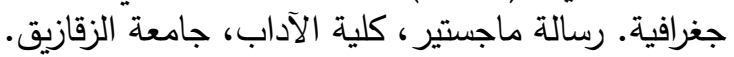

$$
\begin{aligned}
& \text { r. r. • المجلد التاسع والأربعون، العدد التاسع، الجزء السابع، سبتمبر } \\
& \text { الترقيم الدولي 0826-110 110 }
\end{aligned}
$$




$$
\begin{aligned}
& \text { مجلة العلوم البيئية } \\
& \text { معهد الدراسات والبحوث البيئية - جامعة عين شمس لبس } \\
& \text { أحمد منير بهي الدين وآخرون }
\end{aligned}
$$

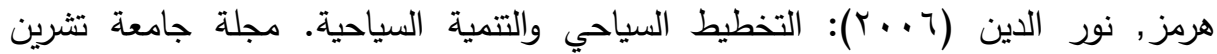

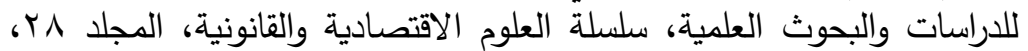

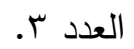

وزارة الإسكان والمرافق والتتمية العمرانية، الهيئة العامة للتخطيط العمراني، إستراتيجية التنمية

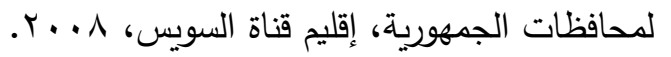

وزارة الدولة لثئون البيئة، جهاز شئون البيئة، التوصيف البيئى لمحافظة الإسماعيلية، V... . .

وزارة الدولة لشئون البيئة، جهاز شئون البيئة، خطة العمل البيئى لمحافظة الإسماعيلية، .r..人

Abdel-Hamid, Yousrya M., Soliman, Mohamed I. and Kenawy, Mohamed A. (2011): Mosquitoes (Diptera: Culicidae) in relation to the risk of disease transmission in El Ismailia Governorate, Egypt. J. Egypt. Soc. Parasitol, 41(2).

Hala Adel Effat and Salwa Farouk Elbeih (2015): Assessment and Evaluation of Land Resources of Suez Canal Region using Remote Sensing and GIS Techniques for Supporting Urban Development Projects. Report to National Authority for Remote Sensing and Space Sciences.

$$
\begin{aligned}
& \text { r. r. • المجلد التاسع والأربعون، العدد التاسع، الجزء السابع، سبتمبر } \\
& \text { الترقيم الدولي 0826-0 الإنوني }
\end{aligned}
$$




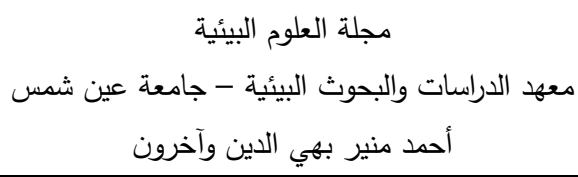

\title{
STRATEGIC ENVIRONMENTAL ASSESSMENT FOR DEVELOPMENT OF ISMAILIA GOVERNORATE USING REMOTE SENSING AND GIS TECHNIQUES
}

\author{
Ahmad M. Bahy EL-Din ${ }^{(1)}$; Hussein M. Isa ${ }^{(2)}$ \\ Mahmoud H. Ahmed ${ }^{(1)}$ and Mohamed G. EL-Malky ${ }^{(3)}$ \\ 1) National Authority for Remote Sensing and Space Sciences \\ 2)Faculty of Commerce, Ain Shams University 3) Institute of \\ Environmental Studies and Research, Ain Shams University
}

\begin{abstract}
The Idea of Development Of Ismailia Governorate considered being one of the most important developmental initiations of the Country seeking to the re-formant structure of the Egyptian inhabited areas to reduce population concentration in the Valley and Delta threatening critically the green agricultural areas in addition to increasing the Environmental Load creating, in turn, lots of health, economic, and social problems. The demand for preserving the environment and its features emerges as an economic problem, In terms of studying Strategic Environmental Assessment through which the natural resources and their appropriate uses are defined besides the positive/negative impacts of the proposed project ,Remote sensing technique and the GIS and satellite images are used for defining the negative and positive impact of the project and establishing cities and urban extensions. The problem, as explained by the strategic environmental assessment results is crystallized in the importance of the huge development projects in pushing the economy wheel and achieve optimal utilization of natural resources that contribute to the restructuring of the Egyptian inhabited area, even if these targeted projects are accompanied by some environmental impacts, that the 450

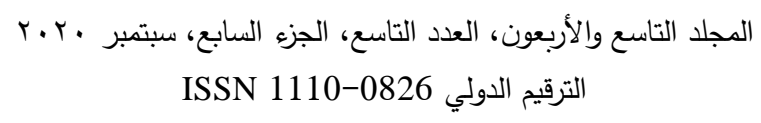




$$
\begin{aligned}
& \text { مجلة العلوم البيئية } \\
& \text { معهد الدراسات والبحوث البيئية - جامعة عين شمس لبس } \\
& \text { أحمد منير بهي الدين وآخرون }
\end{aligned}
$$

study focuses on to clarify them to contribute proposing a researching initiative and reaching applicable solutions, that could be stated in the following axes. The main objective: It is stated in the strategic environmental assessment through the administration of the environmental objectives matrix and balancing between alternatives. Also, the total environmental systems have been submitted as alternatives for sustainable development. The Study relies on the standard method by proposing a comprehensive model that considers the environmental dimensions of the understudied area to reach the best economic development sites. The study also uses the experimental method with semi-experimental procedures and reference to previous Arab and foreign reports, research, references and studies. Digital Transformation processes are used in this study, to obtain digital data of the different geographical features in the study area; added to that, modeling of environmental standards and determinants, which are implemented through the use of several programs using the remote sensing techniques (Erdas Imagine - Envi). Moreover, Geographic information systems (Arc GIS Desktop) program has been used in addition to multiple satellite visuals for monitoring the environmental change rate in the land cover and the digital elevations model (DEM) to build and activate digital models to choose the best development sites according to environmental standards and determinants.

The current study has come out with many results, some of which go following the results of previous studies, including the results of the current study that has already been reached. These results have been included as a Geospatial database for applying the FAO methodology in classifying lands suitability for targeted development; presenting as well, a proposed appropriate development plan, while preserving at the same time the existing economic activities and the optimal utilization of available (natural/human) resources in the surrounding environment.

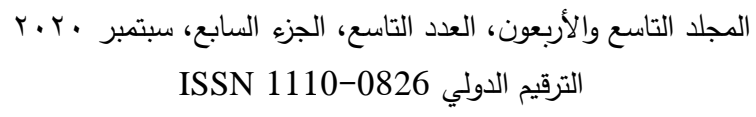




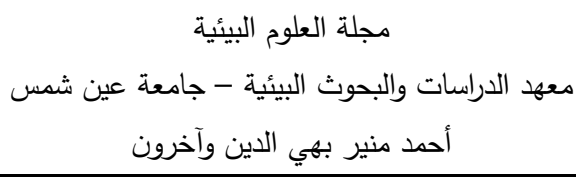

The study recommends the necessity of exploiting the distinguished geographical location of Ismailia Governorate through the proposed sustainable development plane, in attempt to support decisionmaking in linking Sinai and the West of the Suez Canal through targeted development projects through: Optimal use of the available economic resources in Ismailia Governorate depending on the comparative advantage of the existing economic activities such as agricultural reclamation / coastal tourism / fish farming / fishing activities). Announcing that (Al-Timsah Lake) is a Natural Reserve for its environmental unique characteristics that contribute to preserving biological diversity, wild and marine life, with a $200 \mathrm{~m}$. a taboo area set for the lake. Establishing and activating integrated coastal zone management committees to coordinate between research, executive and non-governmental authorities and with participation of civil society organizations (NGO). Utilization of the suitable lands for urban development at a rate of up to $55 \%$ of the total area of the proposed development plan as an important developmental activity for what these lands possess of components compatible with the target development. Attracting the developmental projects to the appropriate areas and developing the infrastructure to encourage internal migration to the expected targeted (urban/industrial) developmental areas.

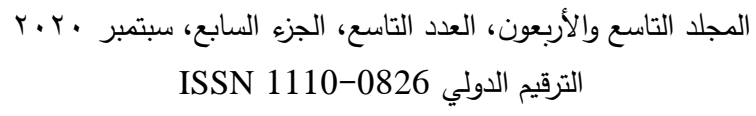

